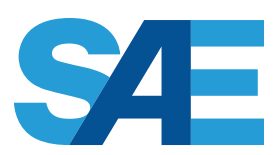

INTERNATIONAL。

\title{
Simulating HCCI Blending Octane Number of Primary Reference Fuel with Ethanol
}

\section{Eshan Singh, Muhammad Waqas, Bengt Johansson, and Mani Sarathy}

King Abdullah University of Science and Technology

CITATION: Singh, E., Waqas, M., Johansson, B., and Sarathy, M., "Simulating HCCI Blending Octane Number of Primary Reference Fuel with Ethanol," SAE Technical Paper 2017-01-0734, 2017, doi:10.4271/2017-01-0734.

Copyright (C) 2017 SAE International

\begin{abstract}
The blending of ethanol with primary reference fuel (PRF) mixtures comprising $\mathrm{n}$-heptane and iso-octane is known to exhibit a non-linear octane response; however, the underlying chemistry and intermolecular interactions are poorly understood. Well-designed experiments and numerical simulations are required to understand these blending effects and the chemical kinetic phenomenon responsible for them. To this end, HCCI engine experiments were previously performed at four different conditions of intake temperature and engine speed for various PRF/ethanol mixtures. Transfer functions were developed in the HCCI engine to relate PRF mixture composition to autoignition tendency at various compression ratios. The HCCI blending octane number $(\mathrm{BON})$ was determined for mixtures of 2-20 vol \% ethanol with PRF70. In the present work, the experimental conditions were considered to perform zerodimensional HCCI engine simulations with detailed chemical kinetics for ethanol/PRF blends. The simulations used the actual engine geometry and estimated intake valve closure conditions to replicate the experimentally measured start of combustion (SOC) for various PRF mixtures. The simulated HCCI heat release profiles were shown to reproduce the experimentally observed trends, specifically on the effectiveness of ethanol as a low temperature chemistry inhibitor at various concentrations. Detailed analysis of simulated heat release profiles and the evolution of important radical intermediates (e.g., $\mathrm{OH}$ and $\mathrm{HO}_{2}$ ) were used to show the effect of ethanol blending on controlling reactivity. A strong coupling between the low temperature oxidation reactions of ethanol and those of n-heptane and iso-octane is shown to be responsible for the observed blending effects of ethanol/PRF mixtures.
\end{abstract}

\section{Introduction}

Spark ignition (SI) and compression ignition (CI) engines have formed the thrust of motive power responsible for much of the progress of today's world. SI engines ignite a homogenous charge as flame is established from a spark, while in CI engines, a stratified mixture of fuel and air ignites in rich equivalence ratio regions and a diffusion flame is formed at the stoichiometric contour. The flames are regions of high temperature, and hence high NOx formation. In a Homogeneous Compression Charge Ignition (HCCI), a homogenous mixture of fuel-air simultaneously autoignites, so there is no flame propagation as such, and the lower temperature leads to very low in-cylinder NOx. Apart from the emission benefits, HCCI engines are able to achieve CI-like efficiency. Market adaption of these engines has not been successful for several reasons: difficulty controlling autoignition and combustion phasing, transient operation, and relatively high $\mathrm{CO}$ and $\mathrm{HC}$ emissions [1]. Researchers have attempted to address a few of these issues using engine technologies such as variable valve timing, variable compression ratio and varying the EGR rate [2]. Honda actually managed to launch a two-stroke motorcycle based on this concept, named Active Radical Combustion (ARC) in 1998 for a short stint, that exhibited 23\% improved fuel economy for same displacement as a conventional four stroke engine [3]. Onishi et al. are credited with introducing the concept in 1979 as active thermo-atmosphere combustion (ATAC) in two stroke engines [4]. The recent push to reduce vehicular greenhouse emissions has increased the interest in HCCI, with its higher efficiency and low emissions of NOx and particulate matter.

Ethanol was one of the early-suggested fuels for use in IC engines. Samuel Morey, widely known as the earliest inventor of Internal Combustion engines, developed engines to run on Turpentine and Ethanol as fuel, in $1826[\underline{5}, \underline{6}, \underline{7}, \underline{8}]$. The blend was known as Camphene. Later in 1860, Nicholaus August Otto used ethanol in his four-stroke engine. As early as 1908, Ford's first car--the Model T--used ethanol based on corn starch. In the 1920's, the Standard Oil Company promoted research on ethanol as an octane-boosting additive. At around the same time, Thomas Midgley and Charles Kettering formulated tetra ethyl lead; and the highly effective nature of the compound and the lower price of gasoline at that time shifted the focus from ethanol to TEL. After TEL was banned (starting in 1975 ) for its toxicity and deleterious effects on the three-way catalyst, MTBE became the world's choice for the next octane booster. However, MTBE was found to contaminate ground water andstarting with California in 2003-it was phased-out, renewing interest in ethanol. Today ethanol is ubiquitous in most of the world in blends ranging from $5 \%$ to $85 \%$ in gasoline. 
The universal presence of ethanol fuel, however, has not translated to its complete understanding of combustion performance in engines. The non-linear trend in octane rating of ethanol with gasoline, as well as surrogates, was pointed out in early literature. Egloff and Morrell (1936) noted the effect of adding ethanol to gas on physical properties like distillation, vapor pressure, and solubility, to engine properties such as anti-knock, acceleration and starting. Their paper discussed the social, economic and political impact of ethanol addition in different blend ratios. They used three different base gasolines and found the non-linear effect to be different for each of them [9]. Alcohol fuels have previously been shown to be better than pure hydrocarbons in HCCI mode of operation, when it comes to the operating range of air-fuel ratios and dilution using Exhaust Gas Recirculation (EGR), as pointed out by Oakley et al [10].

Lichty and Ziurys (1936) found that the benefits from using ethanol (in terms of possible high CR), were offset by the low calorific value of the compound. So that, blended in small quantities, it would be a viable option to enable the anti-knocking behavior of ethanol [11]. Following this, the group studied ethanol blends up to $20 \%(\mathrm{v} / \mathrm{v})$ and found that the anti-knocking behavior of ethanol depends on the base gasoline used [12]. A 1945 study also focused on the effect of ethanol addition in $12 \%, 20 \%$ and $30 \%$ in straight-run gasolines of octane ratings 40,50 and 60 . They found that the octane rating increased by one point for gasolines of octane number 40 and 50, while octane rating increased by an average of 0.8 for 60 octane number gasoline [13]. Another study conducted in 1951, considered research octane number (RON) and motor octane number (MON) tests for increasing ethanol blends in straight run, thermal cracked, catalytically cracked and polymer gasoline and found different octane response with similar ethanol addition [14]. Recent investigations on cooperative fuels research (CFR) engines revealed similar non-linear behavior in RON as well as MON, for gasolines of higher octane ratings $[\underline{15}, \underline{16}]$.

Aromatic content also affects the non-linearity [17]. Foong et al. conducted octane rating tests (RON and MON) on a range of primary reference fuels (PRFs) and Ternary Reference Fuels (TPRF) and found that higher aromatic content leads to lower blending octane numbers; they also found synergistic effects at lower ethanol concentrations.

The inapplicability of conventional octane rating in the HCCI combustion mode has been noted by several researchers [18]. Octane index $[\underline{19}, \underline{20}, \underline{21}]$, Shibata correlation $[\underline{22}, \underline{23}]$, and the Lund-Chevron number [24] have been previously proposed to replace RON/MON for HCCI engine combustion. The effect of adding an octane booster can be better understood in terms of the blending octane number [25] . Blending effect of Ethanol was investigated in a publication in 2016 by Waqas et al. [26]. They chose four conditions to measure the effect of adding a compound: two of these conditions were standard RON/ MON test procedures, but in HCCI mode, while the other two were devised to independently account for the effect of intake temperature and engine speed on fuel behavior. Tests conducted under these operating conditions were used to extract the HCCI number of different fuels, namely, PRF70, PRF 84, FACE A, FACE I and FACE $\mathrm{J}$ (fuels for advanced combustion engines).

Detailed chemical kinetic simulations are a useful tool for understanding HCCI operating conditions since the fuel and air are fully premixed and reactivity of the charge is the governing factor of in-cylinder combustion. Under these conditions, physical properties play a minor role. For this reason, previous researchers used detailed kinetic models to understand combustion behavior $[\underline{27}, \underline{28}, \underline{29}, \underline{30}]$. Several researchers have earlier studied the chemical kinetics behind ethanol addition [31, $\underline{32}]$. Fikri et al. studied ignition delays of Ethanol blended multicomponent fuels in a shock tube to validate kinetic models [32]. The combustion chemistry of ethanol has also been clarified by the use of detailed chemical kinetic modeling [33]. As previously mentioned, single zone chemical kinetic modelling of HCCI engines can be a useful tool for understanding the fuel effect $[\underline{34}, \underline{35}]$. The current study aims to investigate the effect of ethanol addition of a PRF70 mixture. Previous researchers have found ethanol to be more effective at lower concentrations. Chemical kinetics can provide insight into possible reactions for this and further help in fuel designs to maximize the efficiency of future engines. The simulations, based on the heat release analysis, consider the conditions previously used by Waqas et al. [26] .

\section{Methodology}

\section{Experimental Heat Release Analysis}

Experiments were performed on a CFR engine under four different conditions of intake temperature and engine speed. Two conditions match the standard for RON and MON tests while the other two were added to gauge the effect of the two variables on autoignition behavior. Test conditions appear in Table 1 and details are provided in [26]. The valve timing diagram for the engine used is given in Figure 1. The test fuels are blends of PRF70 (70\%vol iso-Octane and 30 $\%$ vol nHeptane) with ethanol in $0 \%, 2 \%, 5 \%, 10 \%, 15 \%$ and $20 \%$ $(\mathrm{v} / \mathrm{v})$. Anhydrous ethanol (purity $>99 \%$ ) was used for the experiments. PRF70 represents low octane gasoline/naphtha fuels. Several literature suggest that these refinery streams could be suitable octane boosters to produce SI engine fuels [36]. Such low octane fuels have earlier proved to be ideal for advanced engine concepts like octane-on-demand, which uses a low octane fuel as its base fuel and an octane booster, as and when required $[\underline{37}, \underline{38}]$.

Table 1. Engine specifications and experimental conditions

\begin{tabular}{|l|l|}
\hline Engine Type & Single cylinder CFR \\
\hline Injection System & Port fuel injection \\
\hline Bore & $82.55 \mathrm{~mm}$ \\
\hline Stroke & $114.3 \mathrm{~mm}$ \\
\hline Connecting Rod & $254 \mathrm{~mm}$ \\
\hline Compression ratio & Variable from $4: 1$ to $15: 1$ \\
\hline Speed & $600,900 \mathrm{rpm}$ \\
\hline Minimum Intake Air Temperature & $52 \pm 2{ }^{\circ} \mathrm{C}$ \\
\hline Maximum Intake Air Temperature & $149 \pm 2{ }^{\circ} \mathrm{C}$ \\
\hline Lambda $(\lambda)$ & 3 \\
\hline
\end{tabular}

Heat release analyses of the experiments were done considering first law analysis and heat losses from heat transfer to the wall, crevices and blow-by losses. This analysis was done on each of the 190 cycles at each operating condition of speed, load and ethanol concentration. Heat release from these 190 cycles are then averaged; the averaged values are reported here. Details on the heat release calculations are mention in Appendix 1. The nomenclature followed throughout the 
text and figures is 'speed/intake temperature' and the fuel used is given by 'E' followed by \% (v/v) blend of Ethanol in PRF70. Therefore, E0 refers to pure PRF70 and similarly for E2, E5, E10, E15 and E20.

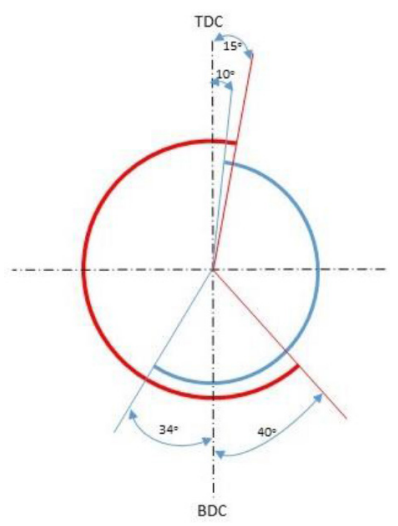

Figure 1. Valve timing diagram for a CFR engine.

\section{Chemical Kinetic Simulation Study}

Initially, the tests conducted on various primary reference fuels (PRFs) were simulated; this was done using the CHEMKIN PRO (ver. 15142) [39] with a closed 0-D single-zone HCCI engine solver. It essentially solves the energy equation with a single phase homogenous charge. The Lawrence Livermore National Laboratory (LLNL) PRF+ethanol kinetic model [40] was employed, with an updated AramcoMech 2.0 based on $\mathrm{C} 0-\mathrm{C} 4$ chemistry [41] and iso-octane sub-mechanism from Atef et al. [42]. The pressure trace was first matched for motoring cases, from the point of the intake valve closing to the point of peak motoring pressure. This gave an equivalent compression ratio to be used for simulations. Thereafter, chemistry was turned on and the combustion phasing was matched. The matching criterion was kept as matching the crank angle for $10 \mathrm{~J} /$ deg of the total heat release rate. The matching criteria considers the heat release rate $(\mathrm{J} / \mathrm{deg})$ and not cumulative heat released $(\mathrm{J})$. The criterion was arbitrary, however it provided good information about the start of combustion. For the fixed compression ratio, intake temperature was varied to achieve similar combustion phasing. Thereafter, this temperature was used for mixtures of ethanol with PRF 70; ethanol was added in 2\%, 5\%, 10\%, 15\% and 20\% (v/v) to PRFs. Hereafter, the compression ratio was increased corresponding to the start of combustion, matching the experimental value. The approach is similar to that followed in experiments, wherein, the CR was increased to match the combustion phasing as CA50 equal to 3 CAD (aTDC), when ethanol concentration is increased from 0 to $20 \%$ $(\mathrm{v} / \mathrm{v})$. Thereafter, a chemical kinetic analysis for the mixtures at these four conditions was performed to explain the non-linear behavior of the blending with different PRFs. Following previous work, it was decided to investigate the rate of heat release (ROHR), $\mathrm{OH}$ and $\mathrm{HO}_{2}$ for this analysis $[\underline{40}, \underline{43}, \underline{44}] . \mathrm{OH}, \mathrm{HO}_{2}$ radicals, temperature and heat release were plotted, which acted as a marker of the reactivity of the mixture at various crank angles [45].

\section{Results and Discussions}

The effect of speed and intake temperature -can be seen in Figure 2. It represents the low temperature heat release (LTHR) values for pure PRF70. Here, it is clear that increasing intake temperature has a drastic effect on LTHR peak, but also increased speed reduces LTHR. Increasing intake temperature and increasing speed leads to lower LTHR.

The result of heat release analysis of the experiments conducted at $600,900 \mathrm{rpm}$ and 52C, 149C with ethanol addition are presented in $\underline{\text { Figures } 3}, \underline{4}, \underline{5}, \underline{6}$. Figure 3 shows the heat released during the low temperature chemistry region at $600 \mathrm{rpm}$ and $52 \mathrm{C}$ intake temperature. Ethanol addition reduces the peak of LTHR drastically. Figure 4 shows LTHR for $600 \mathrm{rpm}$ and 149C. The same trend is observed with ethanol addition as with lower intake temperature. Peak LTHR reduces with increase in temperature and is suppressed at E15 and E20 in this case. Figure 5 shows LTHR for $900 \mathrm{rpm}$ and 52C intake temperature. Ethanol addition, again, reduces the LTHR peak, however addition of ethanol up to $15 \%$ (v/v) does not fully suppress the low temperature heat release. The experiments were conducted only up to E15 for $900 \mathrm{rpm}$ and 52C intake temperature, as the further ethanol addition led to HCCI number moving out of the range of the scale. Moreover, increasing speed from $600 \mathrm{rpm}$ to $900 \mathrm{rpm}$ translates to lower LTHR maximum. $900 \mathrm{rpm}$ and 149C intake temperature case is shown in Figure 6. High temperature coupled with high speed leads to very low LTHR peak even with no ethanol blending. There is negligible low temperature chemistry when ethanol is added at $5 \%(\mathrm{v} / \mathrm{v})$ or more.

It is clear from previous figures that low temperature chemistry reduces with ethanol addition. The peak values of LTHR from each case is now plotted against ethanol addition (v/v) in Figure 7. The peak values are based on change of sign of first derivative of the HRR-CAD curve. Overall, we see the reduction in peak value in all four operating conditions with ethanol addition. The values are not given for all ethanol \% (v/v) cases because LTHR is either negligible or there is no discernable dip after the rise of LTHR. If we consider trendlines for these plots, using linear regression, we observe negative slopes, as shown in Table 2.

Table 2. Slope of linear regression from Figure 6.

\begin{tabular}{|c|c|c|}
\hline Case & Slope of Linear trend line $(\mathrm{J} / \mathrm{deg})$ & $\mathrm{R}^{2}$ \\
\hline $600 / 52$ & -0.2278 & 0.99 \\
\hline $900 / 52$ & -0.2125 & 0.99 \\
\hline $600 / 149$ & -0.1421 & 0.99 \\
\hline $900 / 149$ & -0.1071 & 0.98 \\
\hline
\end{tabular}

The slope reduces with increasing temperature and speed. This points to higher effectiveness of ethanol at reducing LTHR (and therefore, at increasing the resistance to autoignition) at lower intake temperature and lower engine speed. 
Figure 8 shows the location of peak LTHR with ethanol addition for all four conditions. Comparing values at $52 \mathrm{C}$ and $149 \mathrm{C}$, the onset of low temperature heat release is further advanced with increased intake temperature. It is also observed that the retardation of LTHR peak location with ethanol addition is faster at high temperatures, compared to slower retarding at low temperature. The trend with increasing speed is inconclusive; generally pointing to faster retarding low temperature chemistry onset with increasing speed. Here again, with increasing speed, the retardation is faster. Remember that, although the LTHR is shifted, the main heat release was phased nearly similarly in all cases, as CA50 was maintained at +3 CA aTDC in all experiments. This points to a broader intermediate temperature heat release period with increasing intake temperature and speed.

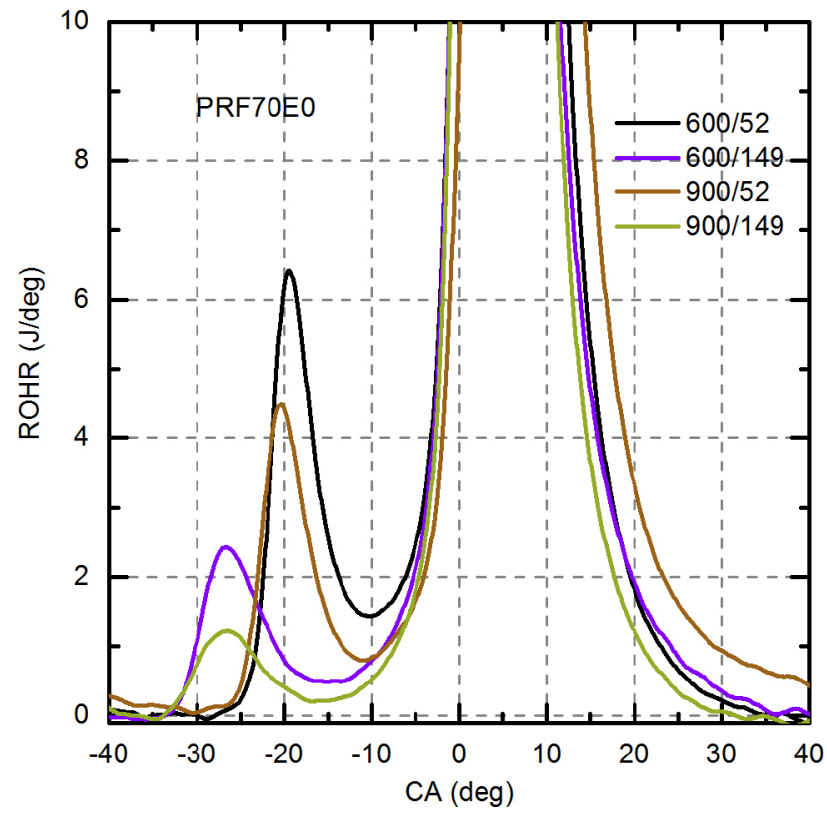

Figure 2. Experimental low temperature heat release for PRF70 at four conditions.

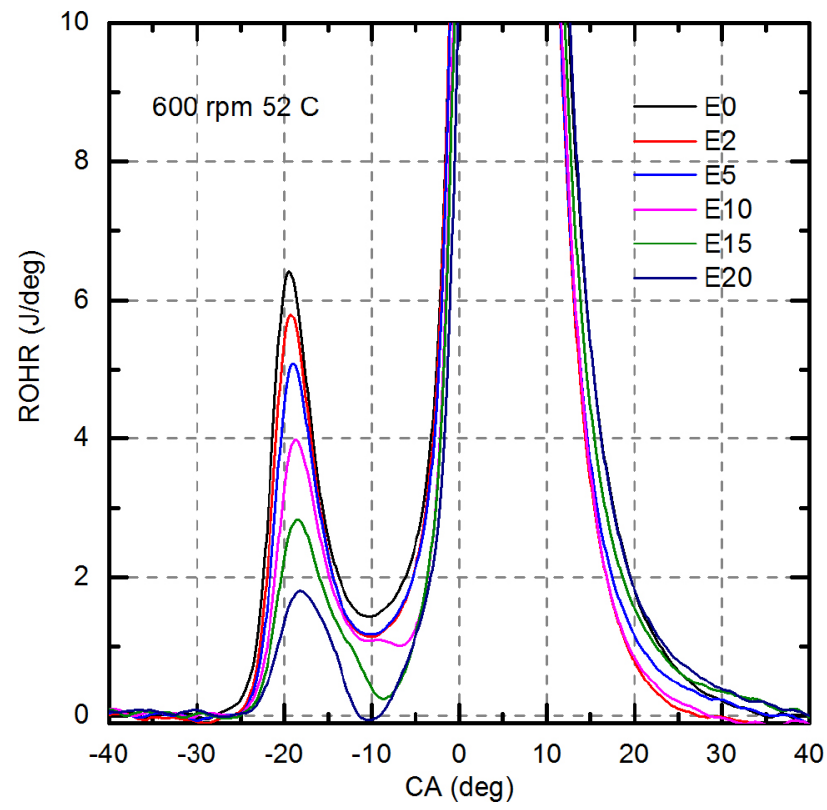

Figure 3. Experimental low temperature heat release for $600 \mathrm{rpm} 52 \mathrm{C}$.

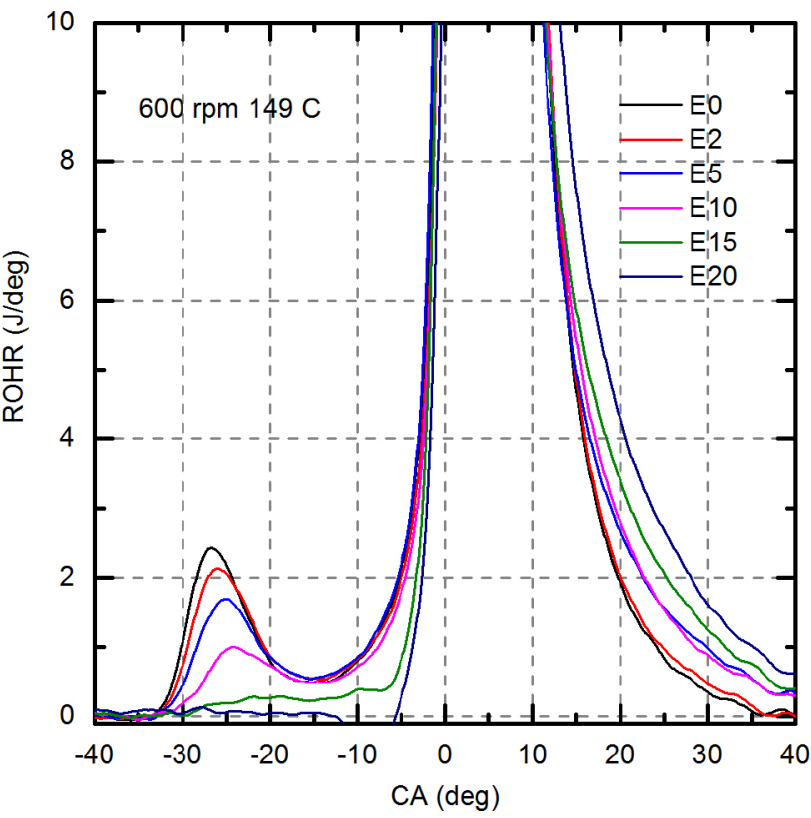

Figure 4. Experimental low temperature heat release for $600 \mathrm{rpm} \mathrm{149C.}$

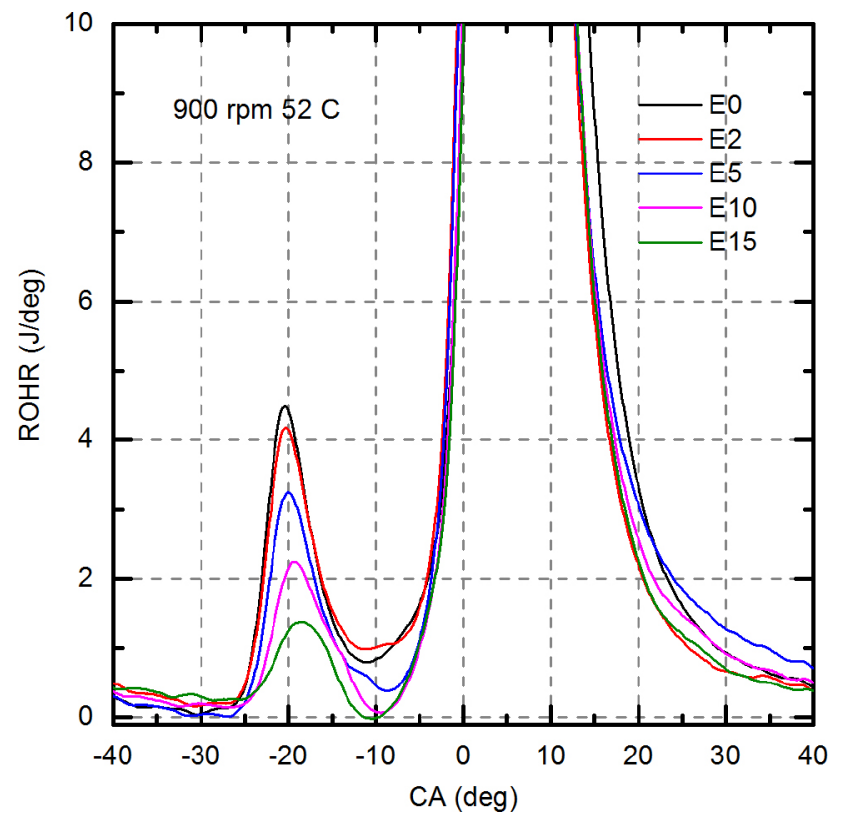

Figure 5. Experimental low temperature heat release for $900 \mathrm{rpm} 52 \mathrm{C}$.

To clarify previous observations from a chemical kinetic point of view, simulations at analogous intake conditions were performed.

As a first step, the experimental pressure trace from the intake to near top dead center (TDC) must be matched in non-reacting cycles. This was done for all PRF70 cases. The intent was to exactly match the pressure at the intake valve closure and start of LTHR. This is similar to matching the in-cylinder conditions in experiments and simulations at the start of any discernable combustion. The motored traces at the compression ratios used in the experiments, which were matched by the simulation are provided in Appendix 2. The compression ratio used in the simulations obtained was lower than that obtained experimentally. This could be attributed to neglecting the heat losses in simulations. The crevice volumes are not considered in 
simulations, due to the geometric crank slider mechanism calculations involved. This also contributes to the disparity in CR observed. According to [ㄴ6], normally the connecting rod's elastic properties are rarely considered when using rigid geometrical calculations of volume based on crank-slider mechanism. This leads to lower $\mathrm{CR}$ values when matching the pressure trace in simulations. The corresponding CR for motoring cases in all four conditions are given in Table 3.

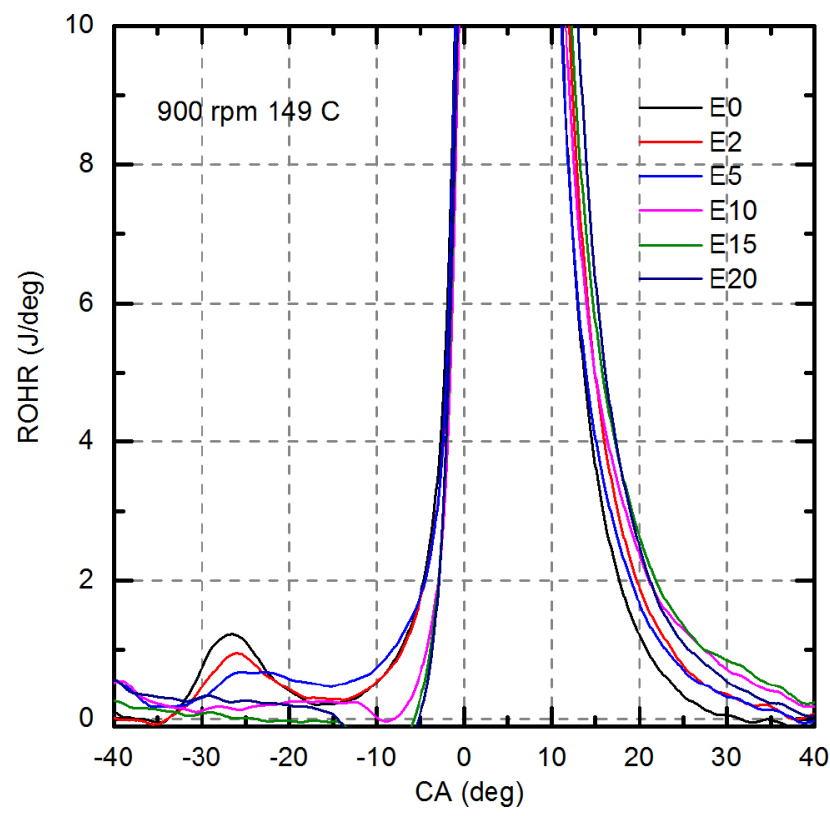

Figure 6. Experimental low temperature heat release for $900 \mathrm{rpm} 149 \mathrm{C}$.

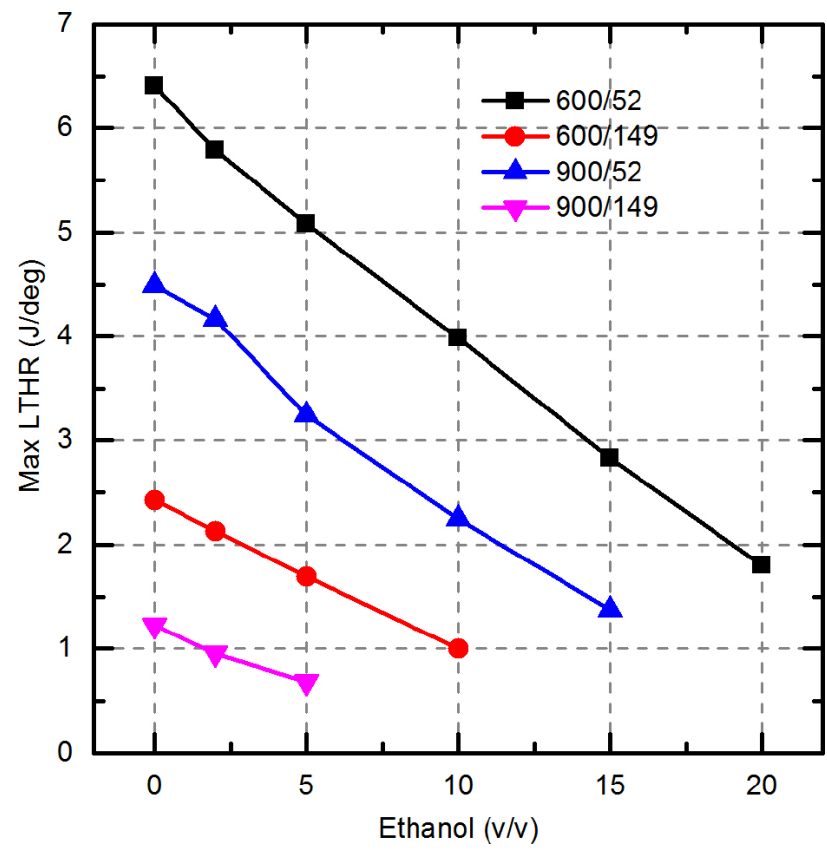

Figure 7. Peak LTHR value for four conditions with varying ethanol concentration. Slopes of linear trend lines are given in Table 2.

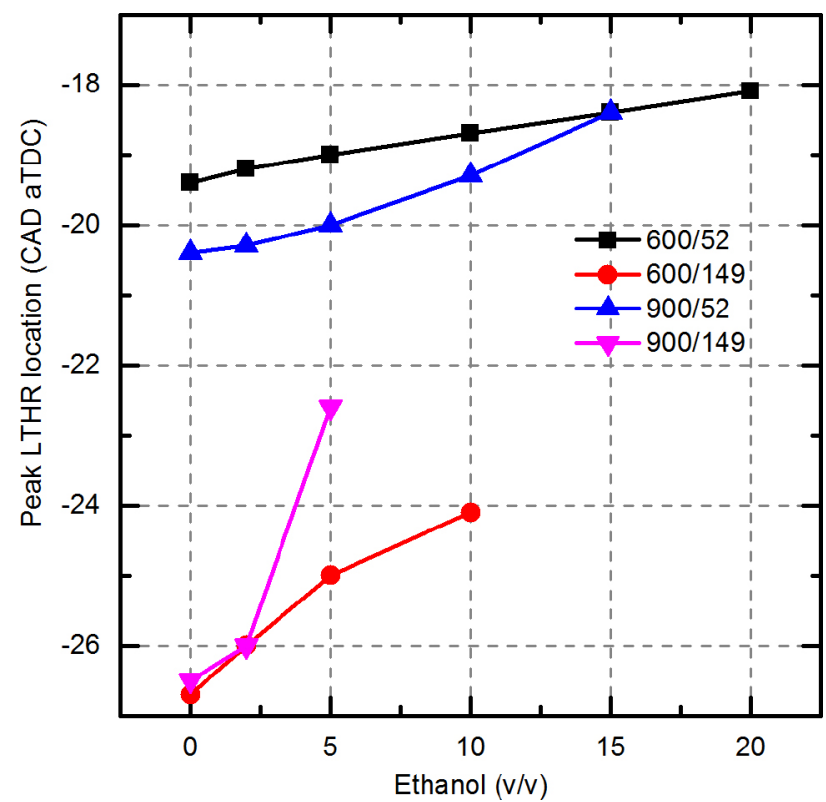

Figure 8. Location of peak LTHR for four conditions with varying ethanol concentration.

Table 3. Simulation baseline inputs.

\begin{tabular}{|c|c|c|c|}
\hline Case & $\begin{array}{l}\text { Experimental } \\
\text { CR }\end{array}$ & $\begin{array}{l}\text { Simulated } \\
\mathrm{CR}\end{array}$ & Simulated $\mathrm{T}_{\mathrm{ivc}}$ \\
\hline $600 \mathrm{rpm} 52 \mathrm{C}$ & 11.1 & 10.8 & $102 \mathrm{C}$ \\
\hline $600 \mathrm{rpm} 149 \mathrm{C}$ & 9.71 & 9.3 & $146 \mathrm{C}$ \\
\hline $900 \mathrm{rpm} 52 \mathrm{C}$ & 11.9 & 11.6 & $120 \mathrm{C}$ \\
\hline $900 \mathrm{rpm} 149 \mathrm{C}$ & 10.92 & 10.6 & $188 \mathrm{C}$ \\
\hline
\end{tabular}

The four independent cases of engine speed and intake temperature were simulated. The engine speed was fixed based on the experiments, but the intake temperature had to be varied to achieve SOC at the same crank angle as the experiments. For the lower intake temperature cases with $52 \mathrm{C}$ in the experiments, the simulated intake temperature was increased by $50-68 \mathrm{C}$ to achieve similar SOC phasing. This increased intake temperature is attributed to several reasons discussed below:

- The temperature used for simulations is the intake valve closure, and not the intake air temperature higher upstream of the intake system. Moreover, as the simulations are single phase homogeneous, $0-\mathrm{D}$, it reflects the temperature of the bulk, where reactions take place, which is again different from the temperature close to the wall [ㅍ].

- There is no consideration for exhaust gas recirculation mass. Roughly, it scales with the inverse of CR and the exhaust temperature is in the range of $300 \mathrm{C}$. Considering the upper bound, it can lead to $30 \mathrm{C}$ increment in temperature of the bulk charge.

- The heat losses have not been considered in the simulations. This also includes the exclusion of transient heat transfer from the wall as the piston moves.

- Woschini coefficient is used to find a zero baseline curve for the motoring curves (leading to no heat release). An error in estimation of Woschini coefficient can drastically change the temperature estimation. 
- There is heat transfer from the valves and inlet manifold. For intake air temperature higher than valve temperature, this effect would lead to charge cooling and vice-versa.

- Because of gas phase homogenous assumption, charge cooling due to latent heat of vaporization was not taken into account in the model. This can lead to reduction in bulk gas temperature. Inclusion of above factors can explain a difference of upto 40 $\mathrm{C}$ between experiments and simulation. Vuellemier et al used 1-D simulations to estimate the temperature at IVC and found considerably high values accounted from EGR and charge heating from metal surfaces [푸] .

- A lack of reactivity in the LLNL chemical kinetic model, especially under HCCI engine operating conditions has been encountered by previous researchers $[30, \underline{47}]$. The detailed chemical kinetic model has been validated against fundamental experiments in shock tubes and rapid compressions machines, so modifying the kinetic rate constants to match the HCCI engine data is not a suitable approach to resolving the discrepancy.

For these reason, the intake temperature was increased to compensate for the lower reactivity in the kinetic model. Moreover, the correct estimation includes exact mass of EGR, valve temperature, wall temperatures and transient heat losses from the wall to the bulk charge and consideration of thermal boundary layer thickness $[\underline{49}, \underline{50}]$. These effects compete to raise or lower the bulk temperature, which needs to be used for a zero dimensional simulation, as explained above. As will be shown later, this modification did not impact the ability to understand the effect of ethanol blending on HCCI engine ignition and heat release.

Appendix 3 shows the various cases mentioned before and the corresponding heat release rates from experiments and simulations for various ethanol concentrations. Figure 9 compares the simulated LTHR for all blends at 600 RPM 52C. The start of the main high temperature heat release was aligned between the experiments and simulations, which allowed comparison of the chemical kinetics contributing to HRR to this point. The PRF70E0 mixtures showed a prominent first-stage ignition and corresponding LTHR peak around - $20 \mathrm{CAD}$ in both the experiment and simulation. This was followed by a delay period before the second-stage ignition and high temperature heat release (HTHR). The addition of $2 \%$ ethanol to PRF 70 (PRF70E2) resulted in a notable decrease in LTHR, as observed in both numerical simulation and experiment. Increasing the volume fraction of ethanol further decreased the magnitude of LTHR. At 15\% ethanol addition, LTHR was substantially lower in the experiment and largely non-existent in the simulation. The simulation for PRF70E15 and PRF70E20 predicted that the LTHR was completely suppressed. The decrease in LTHR per unit addition of ethanol appeared to be nearly linear, which was in agreement with the effect of ethanol blending on the HCCI numbers measured by Waqas et al. [26].

Several engine combustion studies $[\underline{48}, \underline{51}, \underline{52}]$ have shown that ethanol suppresses LTHR, but this was rationalized as a thermodynamic, or charge cooling affect; the underlying chemistry of ethanol as a radical scavenger is often overlooked. Here, the attempt was to provide a more fundamental explanation of the chemical kinetics of PRF mixtures with ethanol. First, it was noted that the two-stage ignition with negative temperature coefficient (NTC) behavior observed for PRF70 is typical of paraffinic fuels, and is attributed to the competition between various low temperature radical chain branching and chain termination reaction pathways $[\underline{53}, \underline{54}, \underline{55}, \underline{56}, \underline{57}, \underline{58}]$. The low temperature oxidation pathways ultimately impact the size and nature of the radical pool that is generated, which in turn drives the ignition process. The most important radicals in the low temperature ignition process are the hydroxyl $(\mathrm{OH})$ and hydroperoxyl $\left(\mathrm{HO}_{2}\right)$ radicals.

Figures 10 and 11 show the underlying $\mathrm{OH}$ and $\mathrm{HO}_{2}$ radicals formed in the Low temperature region for the same conditions. Plots are on log-scale, and the evolution of $\mathrm{OH} / \mathrm{HO}_{2}$ radicals closely follow any heat release in the Low temperature regime. The mechanism involved has been described in detail in previous literature $[\underline{59}, \underline{60}, \underline{61}, \underline{62}]$. Briefly, PRF mixtures display significant LTHR and 2-stage ignition characteristics due to the low temperature radical chain branching pathways that lead to formation of ketohydroperoxides and eventually $\mathrm{OH}$ radical production. The process is initiated by the formation of peroxy radicals from the reaction of fuel radicals with molecular oxygen. The peroxy radicals isomerize at low temperatures, and the intermediates undergo subsequent reaction with molecular oxygen to form ketohydroperoxides and $\mathrm{OH}$ radicals. As temperature rises during the LTHR event, competing radical chain termination pathways, such as the formation of alkenes and $\mathrm{HO}_{2}$ radical via concerted elimination form peroxy radicals, become important and suppress reactivity. As the $\mathrm{HO}_{2}$ radical pool builds up, these radicals react with the fuel to form $\mathrm{H}_{2} \mathrm{O}_{2}$, which eventually decomposes to $2 \mathrm{OH}$ radicals and results in HTHR. It is clear from Figure 10, that PRF 70 displays a prominent $\mathrm{OH}$ radical peak near the LTHR region, followed by decreased $\mathrm{OH}$ radical concentration in the intermediate temperature region, and ultimately significant increase at HTHR. The $\mathrm{HO}_{2}$ radical concentration follows a similar trend, albeit it does not span as a large range of concentrations as $\mathrm{OH}$ radical; the former spans an order of magnitude in the LTHR-HTHR region while the latter spans 2 or more orders of magnitude. The addition of ethanol to PRF suppresses the LTHR by means of suppressing $\mathrm{OH}$ radical production in the LTHR region. Ethanol effectively suppresses $\mathrm{OH}$ radical production by acting as a radical sink. The $\mathrm{C}-\mathrm{H}$ site next to the hydroxyl moiety in ethanol has very low bond dissociation energy, and can easily be abstracted by $\mathrm{OH}$ radicals. The subsequent alpha-hydroxyethyl radical does not undergo conventional low temperature radical chain branching pathways, as PRF fuels do. Instead, the ethanol fuel radical reacts with molecular oxygen to form acetaldehyde and $\mathrm{HO}_{2}$ via a fast concerted reaction. The net result is a significant decrease in $\mathrm{OH}$ radical production with increased ethanol blending, as shown in Figure 10, but only a marginal decrease in $\mathrm{HO}_{2}$ radical production, as shown in Figure 11. This rationalizes why ethanol suppresses the LTHR when blended with ethanol but still allows for production of $\mathrm{HO}_{2}$ radicals in the intermediate temperature regime to facilitate HTHR. 
Figure 12 further shows the magnitude of peak LTHR in J/deg. The trend in Figure 12 is similar to the trend seen previously in experiments. It can be observed that the peak LTHR reduces with increasing ethanol concentration.

Moreover, the effectiveness of ethanol as an octane booster can now, also be explained by the fact that LTHR is further early the compression stroke, as seen in Figure 13. More retarded values of peak LTHR in Figure 13 means the peak temperature from the LTHR is reached earlier in the compression stroke, that the whole LTHR is shifted in CAD, more prominently seen for E0 cases in Figure 2. This can be understood in the following way: Suppose $T_{1}$ and $T_{2}$ are the in-cylinder temperature at the start and end of LTHR. As ethanol concentration is increased, a more retarded start of LTHR translates to higher $\mathrm{T}_{1}$. Assuming same amount of heat is released in the process, the temperature increase is same for all ethanol concentration cases $\left(\Delta T=T_{2}-T_{1}\right)$. This means a lower $T_{2}$ for lower ethanol concentration, due to more advanced start of LTHR with reducing ethanol concentration. Assuming an isentropic compression from thereon until the advent of HTHR (at some fixed temperature $\mathrm{T}_{3}$ ), a lower ethanol concentration will take longer to transition to HTHR. This is because it will take longer to increase the temperature from $\mathrm{T}_{2}$ to $\mathrm{T}_{3}$ for lower ethanol concentration, meaning higher ignition delay time, which leads to resistance to autoignition.

Now if we remove the assumption of constant heat released during the LTHR from above discussion; it was observed in Fig. 6 that total heat released decreases rapidly with increasing ethanol concentration. This translates to a lower rise in temperature for higher ethanol concentration. This would mean that $\mathrm{T}_{2}$ is lower for higher ethanol concentration. A lower $\mathrm{T}_{2}$ means a higher delay to reach $\mathrm{T}_{3}$, hence a higher resistance to autoignition. These two are competing mechanisms and the resulting octane rating would generally be a coupling of the two. The weightage to any of these factor depends on the speed-load condition as shown in Fig. 7 and may lead to a non-linear octane behavior depending on which is the governing factor.

It needs to be considered that in the experiments as well as simulations, CR was varied to achieve same CA50 for varying ethanol concentration. A higher CR would lead to a faster rise in temperature and hence that also needs to be considered, a scope of future investigation.

The peak $\mathrm{OH}$ and $\mathrm{HO} 2$ are also plotted in Figure 14. The $\mathrm{OH}$ radical correlates well the peak LTHR values, drastically reducing with $2 \%$ $(\mathrm{v} / \mathrm{v})$ ethanol addition and steadily decreasing thereafter. However, the $\mathrm{HO}_{2}$ radical does not correlate with the reduction in $\mathrm{OH}$, as discussed before.

Considering the case of $600 \mathrm{rpm}$ and $149 \mathrm{C}$ intake temperature, Figure 15 shows reduced LTHR with the addition of ethanol. Under these conditions, ethanol was highly effective in suppressing LTHR as ethanol; as low as $2 \%(\mathrm{v} / \mathrm{v})$ leads to negligible LTHR. This can be verified in Figure 16 and Figure 17, which again display $\mathrm{OH}$ and $\mathrm{HO}_{2}$ radical production that directly relates to the reactivity of the mixture.

Figure 18 shows the heat released during low temperature reactions for the case of $900 \mathrm{rpm}$ and $52 \mathrm{C}$. The omission of E20 results has to do with how the experiments were performed. E20 yielded CR values that were beyond the upper limit of the transfer function generated, hence not considered for the simulations also. The peak LTHR value is much lower compared to the previous case, even with no ethanol blending. However, the addition of ethanol was equally effective in suppressing LTHR, as can be seen again in Figure 19 . Adding $2 \%$ of ethanol can be seen to almost fully suppress the LTHR. Figures 19 and 20 show the $\mathrm{OH} / \mathrm{HO}_{2}$ radicals for the case.

Figure 21 shows the LTHR for $900 \mathrm{rpm}$ and $149 \mathrm{C}$ case. As previously shown, low temperature chemistry is reduced with increasing speed and intake temperature. This condition is the most adverse of the four, hence very low LTHR should be observed. Experimentally, it can be seen that LTHR is negligible with the addition of ethanol in 5\% or more (v/v). Simulations match the experimental criteria, so the LTHR values are even lower. Nevertheless, very little LTHR can be seen in the case of zero ethanol content PRF70, while it is completely suppressed with the addition of any amount of ethanol (igure 21). Figures 22 and 23 , which show the $\mathrm{OH}$ and $\mathrm{HO} 2$ radical, further corroborate this fact. No LTHR at E5 and higher warrants the omission of the rest of the data points in this case.

Overall, the effect of ethanol addition is seen to be highly effective at low intake temperature conditions. A small addition of ethanol reduced the LTHR drastically; thereafter LTHR is almost completely suppressed by PRF70E20 in almost all cases. It can be hypothesized that, for each mole of ethanol, there is a greater number of moles of compounds exhibiting low temperature radical chain branching chemistry (primarily $\mathrm{n}$-heptane and iso-octane here). Hence, any amount of ethanol reacts with a large pool of $\mathrm{OH}$ radicals generated by the alkanes. Therefore, the scavenging efficacy is greater when ethanol is blended at lower concentrations when compared to higher concentrations. At higher mole fractions, the total $\mathrm{OH}$ radical pool is lower due to the decreased amount of alkanes. As a result, ethanol has less $\mathrm{OH}$ radicals to scavenge and becomes comparably less effective at reducing LTHR. As a consequence, ethanol ability to increase the octane number on a per mole bases is decreased in increased ethanol concentration.

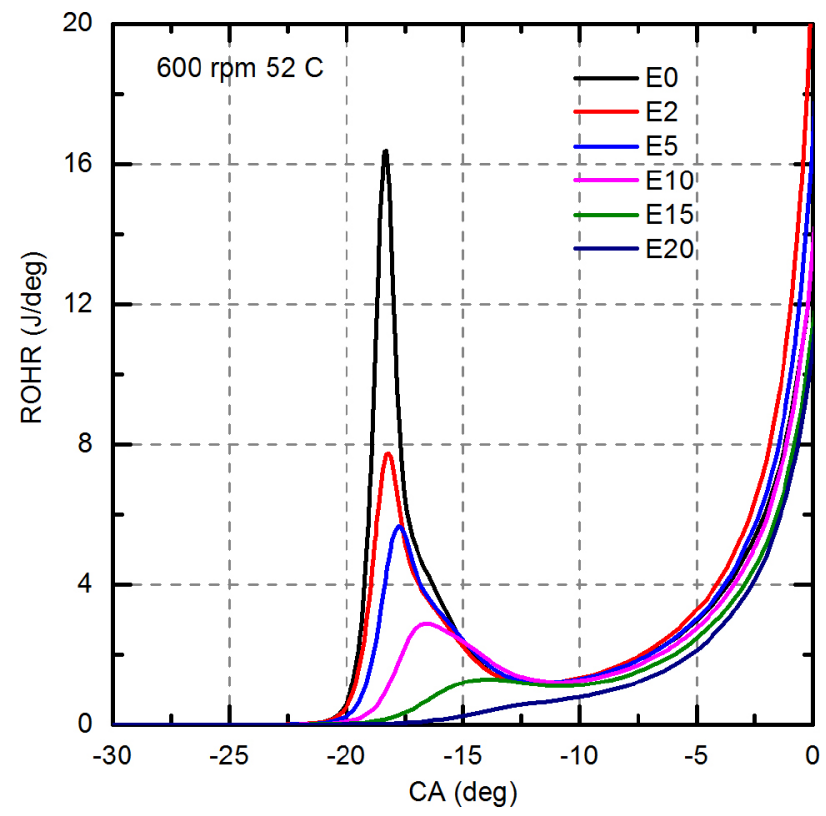

Figure 9. Comparing ROHR for varying ethanol concentrations at $600 \mathrm{rpm}$ and $\mathrm{T}_{\mathrm{ivc}}$ (estimated) $102 \mathrm{C}$ 


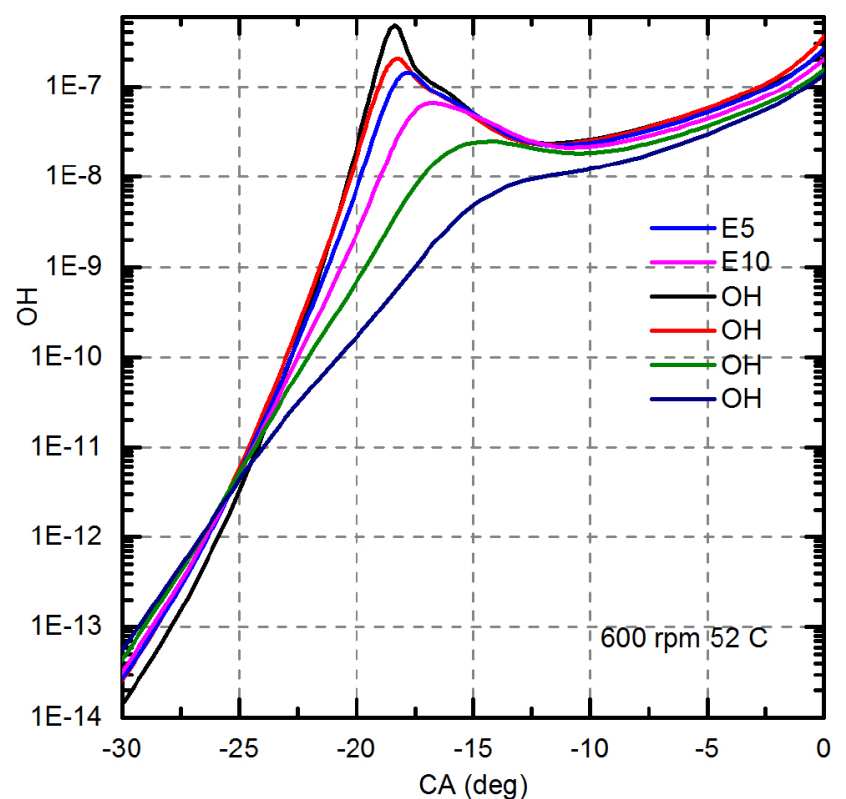

Figure 10. OH mole fraction for varying ethanol concentrations at $600 \mathrm{rpm}$ $\mathrm{T}_{\text {ivc }}$ (estimated) $102 \mathrm{C}$.

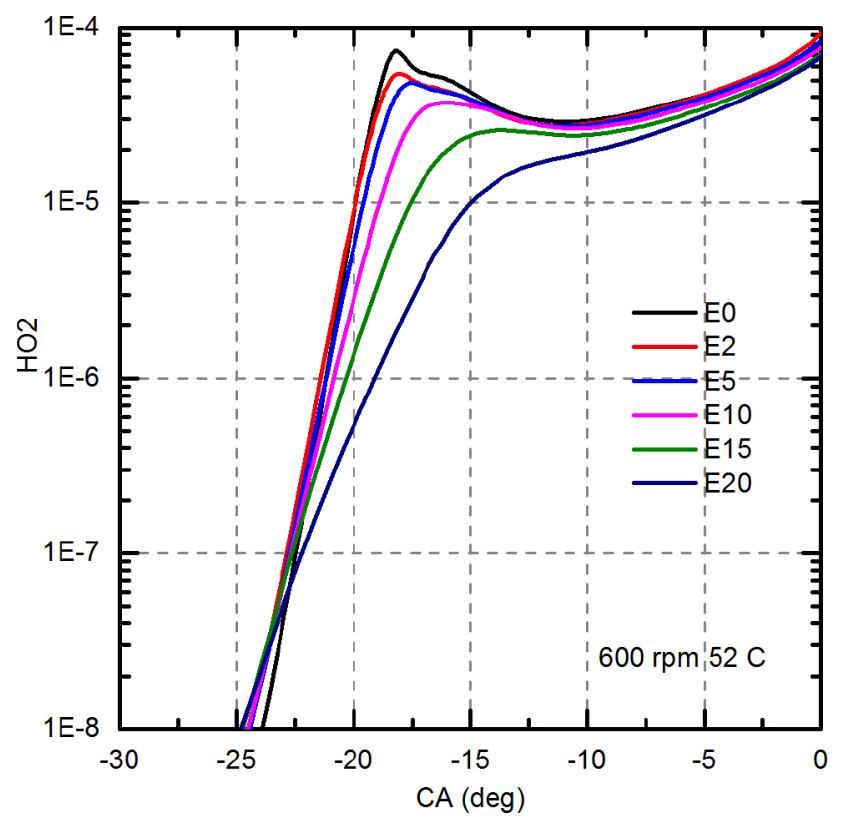

Figure 11. $\mathrm{HO}_{2}$ Concentration for varying ethanol concentrations at $600 \mathrm{rpm}$ $\mathrm{T}_{\mathrm{ivc}}$ (estimated) $102 \mathrm{C}$.

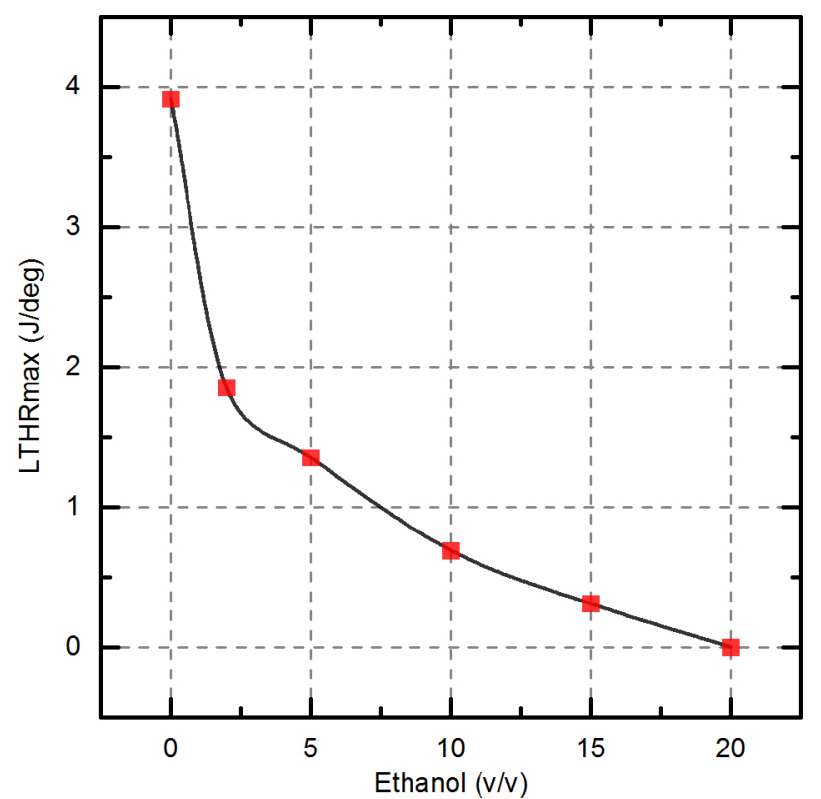

Figure 12. Maximum LTHR with varying ethanol concentrations for 600rpm and $52 \mathrm{C}$ intake air temperature.

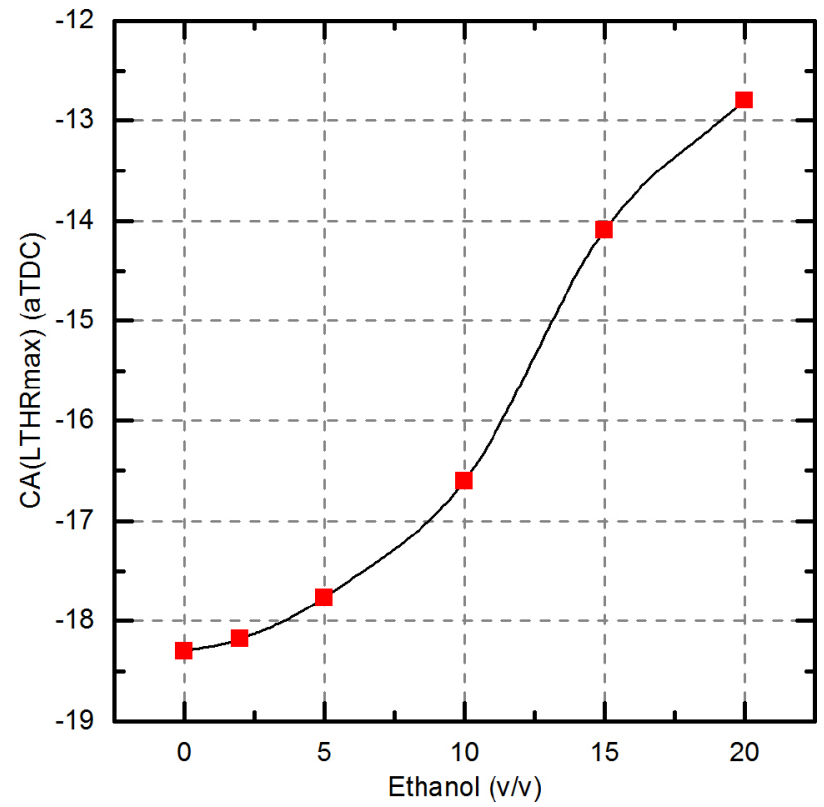

Figure 13. Location of peak LTHR (CAD aTDC) with varying ethanol concentrations for $600 \mathrm{rpm}$ and $52 \mathrm{C}$ intake air temperature. 


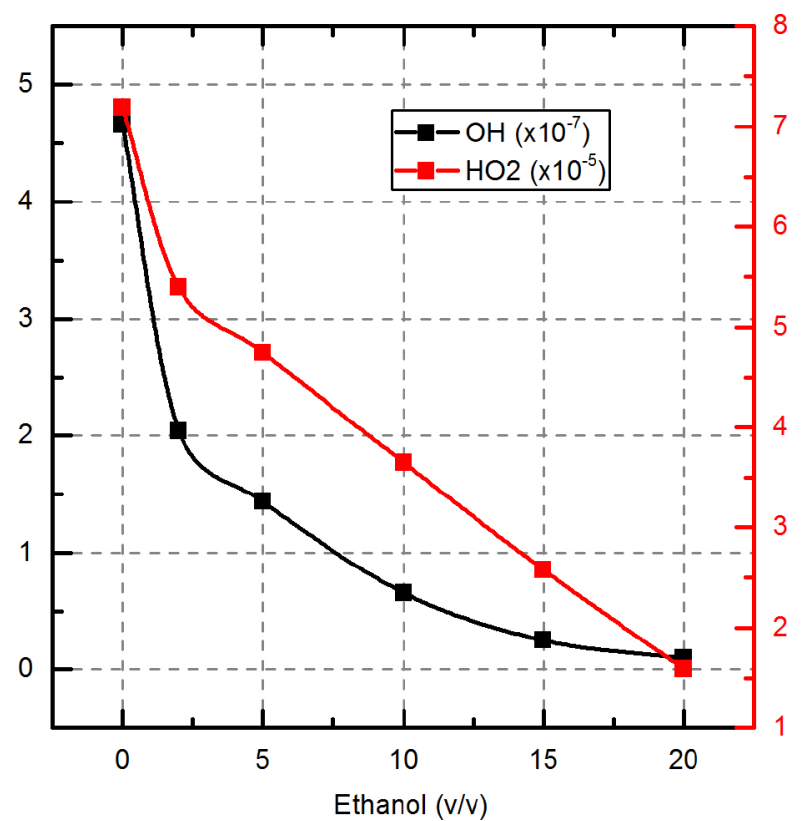

Figure 14. Peak $\mathrm{OH}$ and $\mathrm{HO} 2$ values with varying ethanol concentrations.

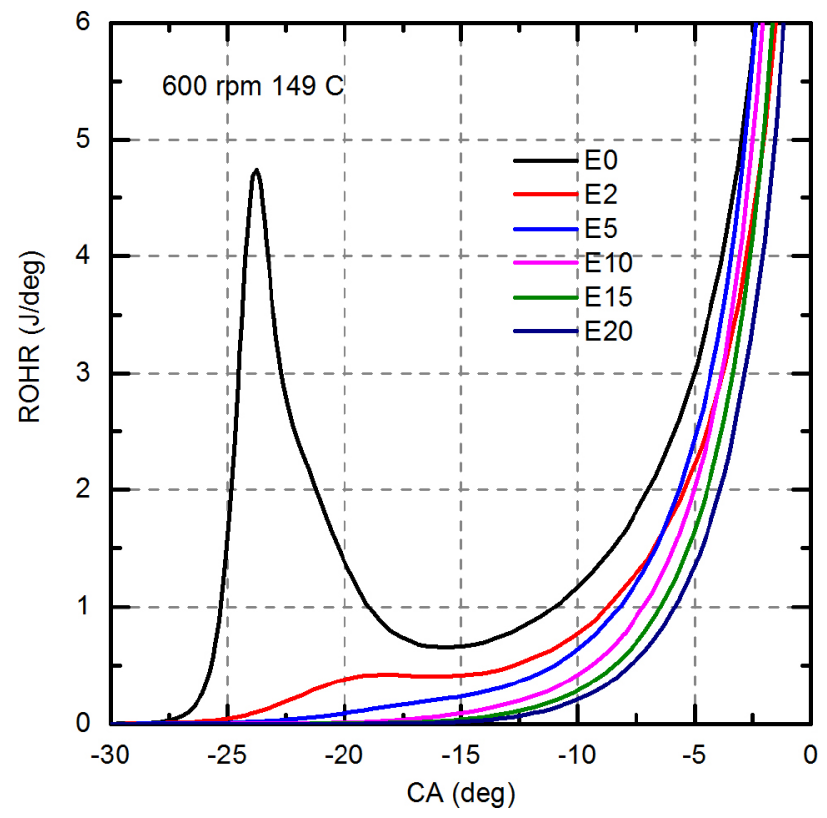

Figure 15. Comparing ROHR for varying ethanol concentrations at $600 \mathrm{rpm}$ $\mathrm{T}_{\text {ivc }}$ (estimated) $146 \mathrm{C}$

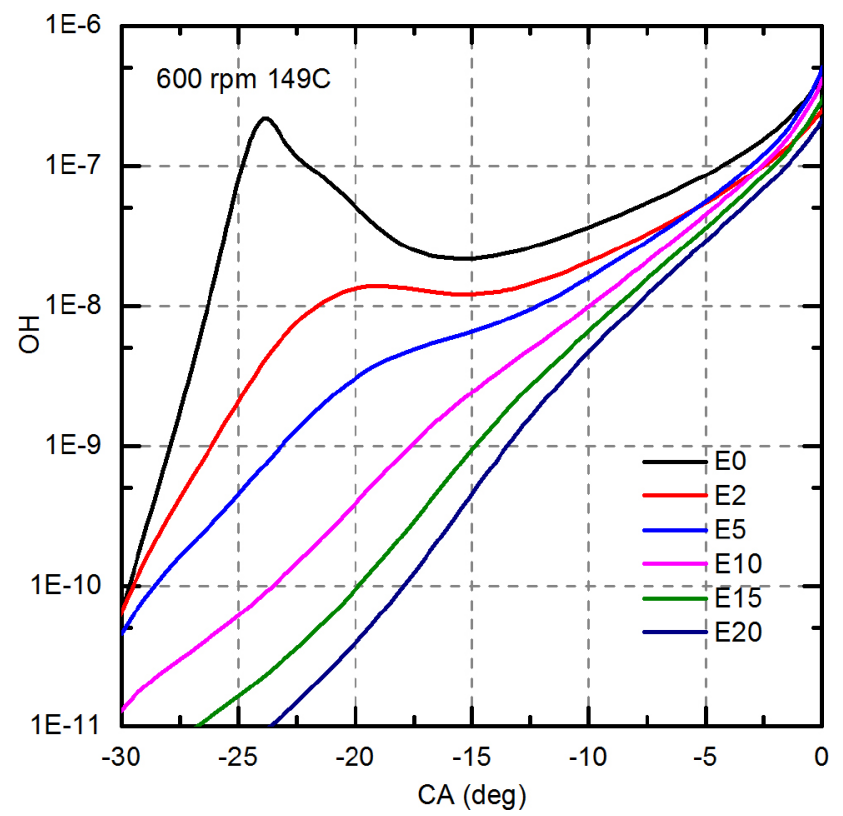

Figure 16. OH mole fraction for varying ethanol concentrations at $600 \mathrm{rpm}$ $\mathrm{T}_{\text {ivc }}$ (estimated) $146 \mathrm{C}$.

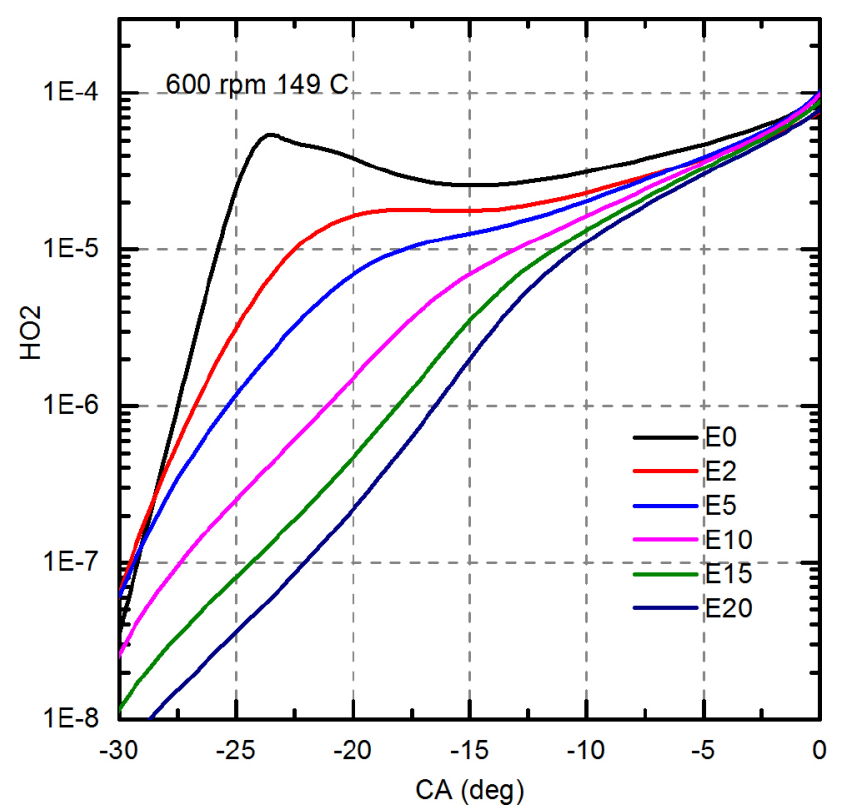

Figure 17. $\mathrm{OH}$ mole fraction for varying ethanol concentrations at $600 \mathrm{rpm}$ $\mathrm{T}_{\mathrm{ivc}}$ (estimated) 146C. 


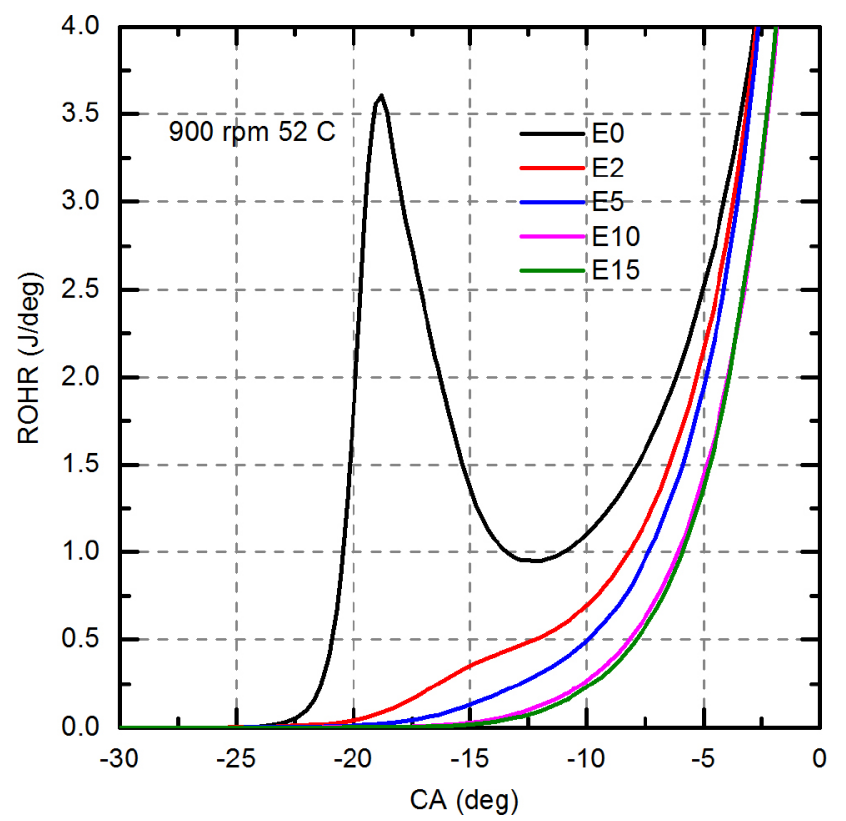

Figure 18. Comparing ROHR for varying ethanol concentrations at $900 \mathrm{rpm}$ $\mathrm{T}_{\mathrm{ivc}}$ (estimated) $120 \mathrm{C}$

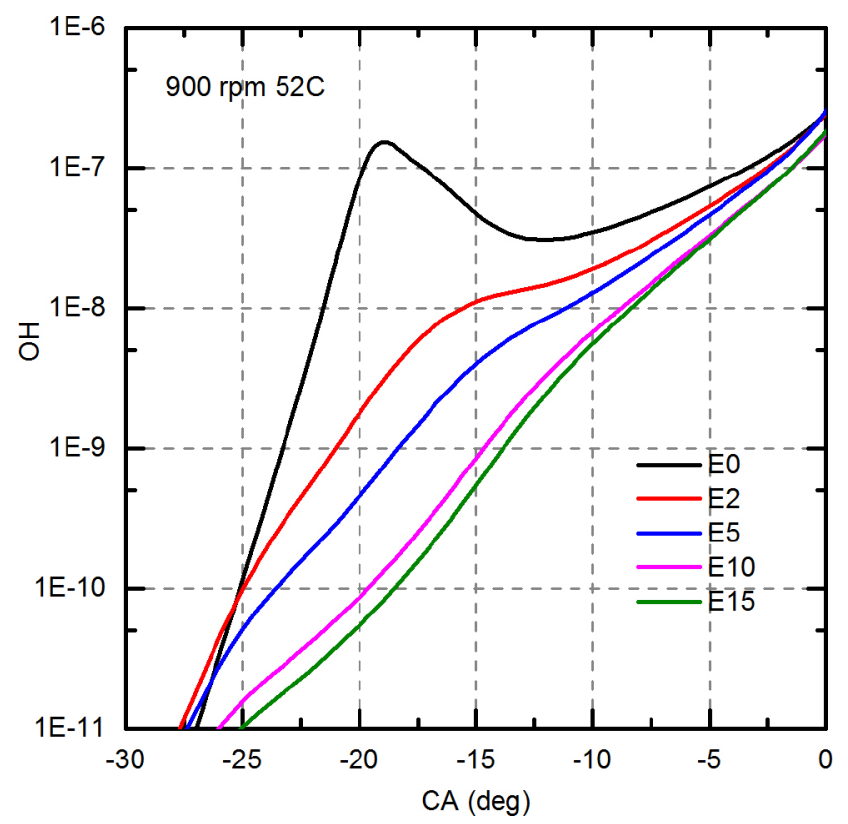

Figure 19. OH mole fraction for varying ethanol concentrations at $900 \mathrm{rpm}$ $\mathrm{T}_{\text {ivc }}$ (estimated) 120C.

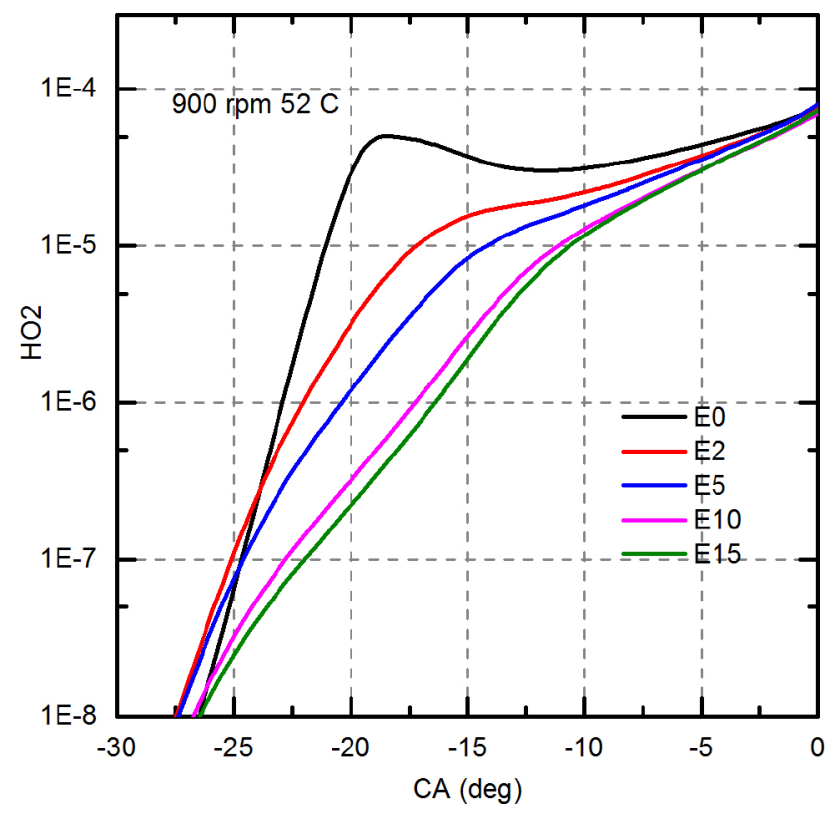

Figure 20. $\mathrm{HO}_{2}$ mole fraction for varying ethanol concentrations at $900 \mathrm{rpm}$ $\mathrm{T}_{\mathrm{ivc}}$ (estimated) $120 \mathrm{C}$.

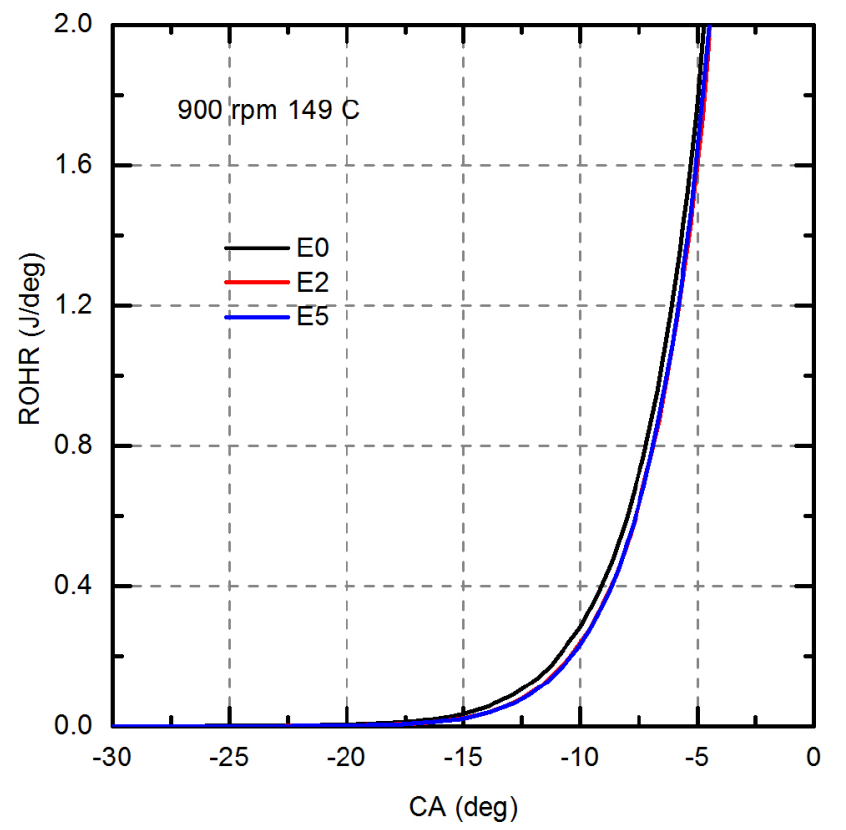

Figure 21. Comparing ROHR for varying ethanol concentrations at $900 \mathrm{rpm}$ $\mathrm{T}_{\text {ivc }}$ (estimated) $188 \mathrm{C}$ 


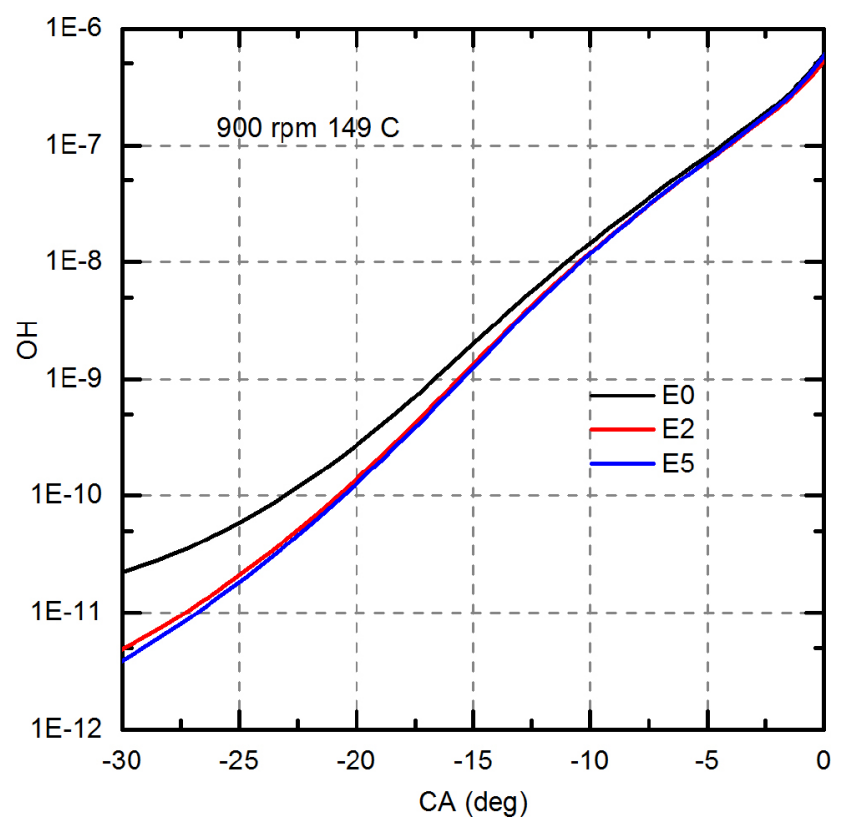

Figure 22. OH mole fraction for varying ethanol concentrations at $900 \mathrm{rpm}$ $\mathrm{T}_{\mathrm{ivc}}$ (estimated) $188 \mathrm{C}$.

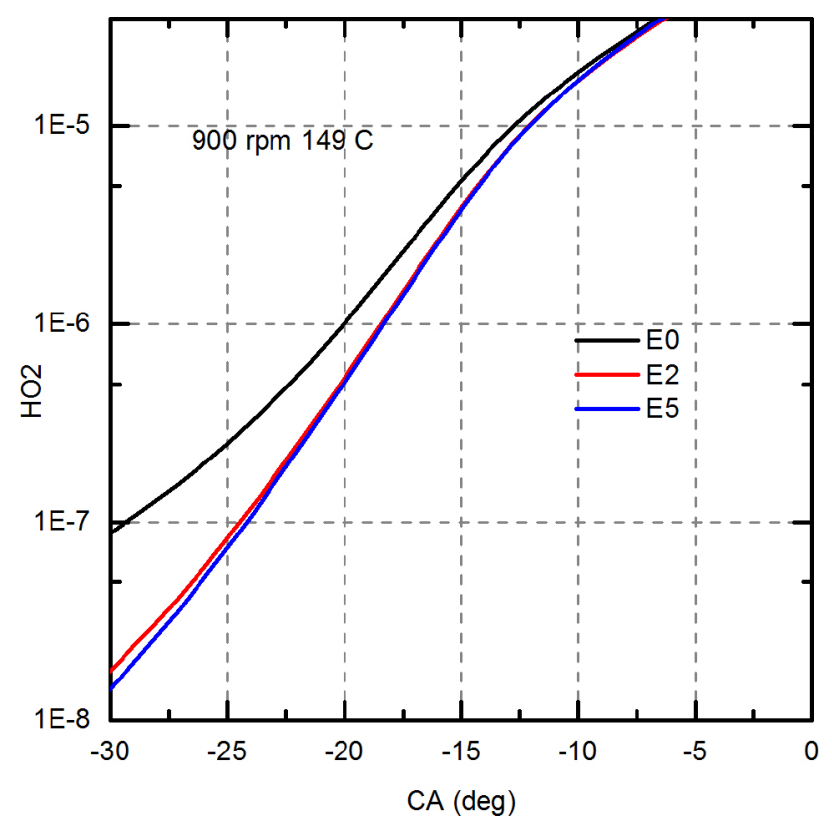

Figure 23. $\mathrm{HO}_{2}$ mole fraction for varying ethanol concentrations at $900 \mathrm{rpm}$ $\mathrm{T}_{\mathrm{ivc}}$ (estimated) $188 \mathrm{C}$.

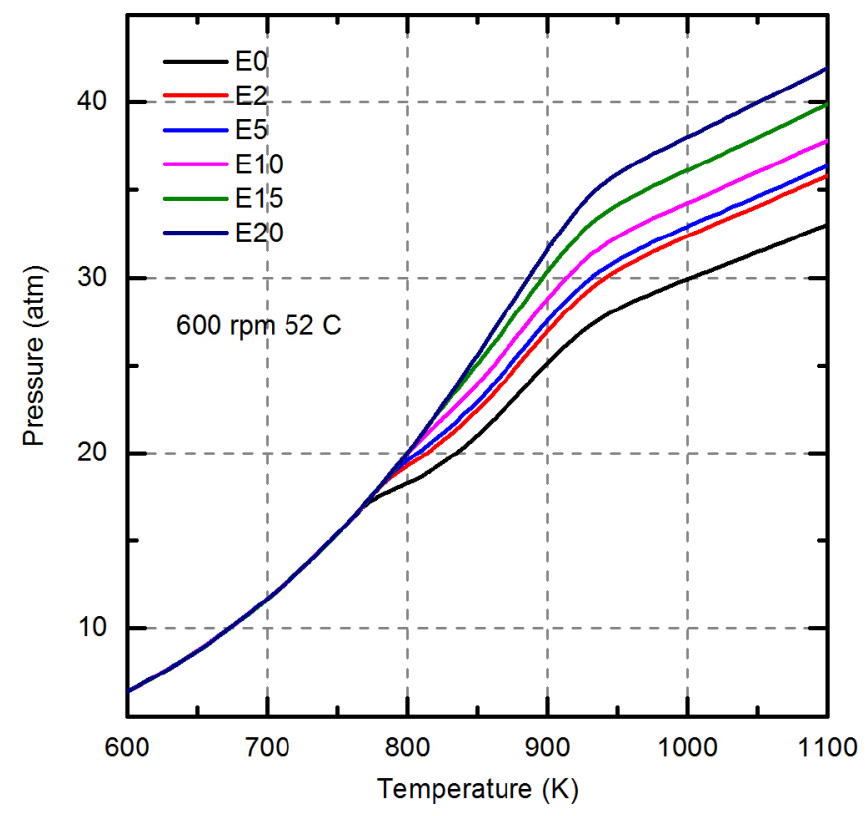

Figure 24. Simulated Pressure vs Temperature for $600 \mathrm{rpm}$ and $52 \mathrm{C}\left(\mathrm{T}_{\mathrm{ivc}}\right.$ (estimated) 102C) case.

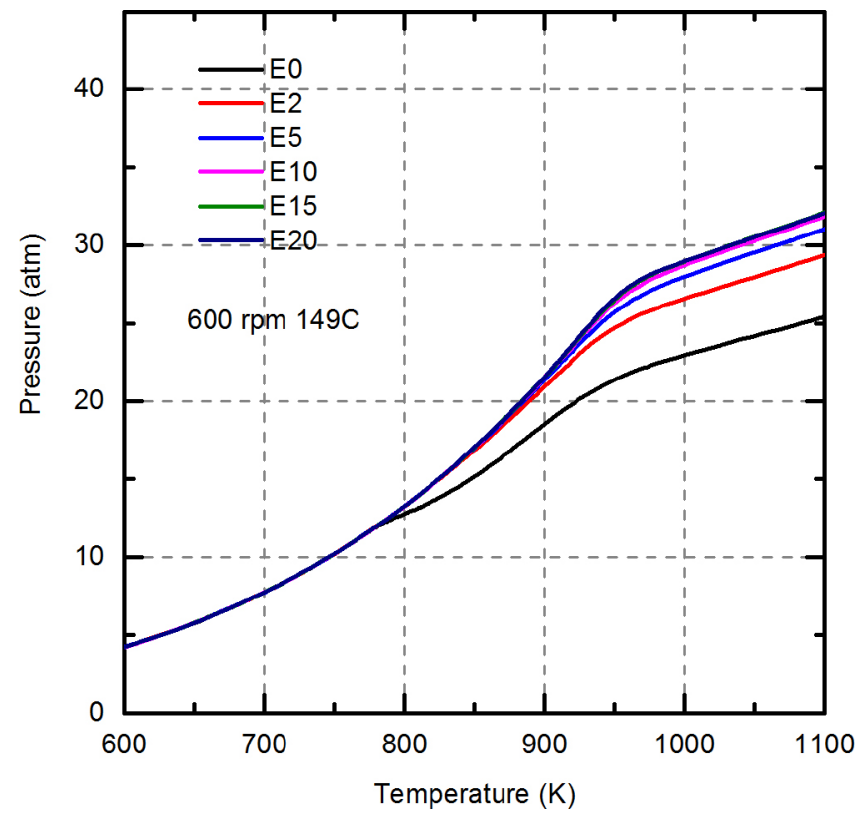

Figure 25. Simulated Pressure Temperature plot for $600 \mathrm{rpm}$ and $149 \mathrm{C}$ (estimated $\mathrm{T}_{\text {ivc }} 146 \mathrm{C}$ ) case 


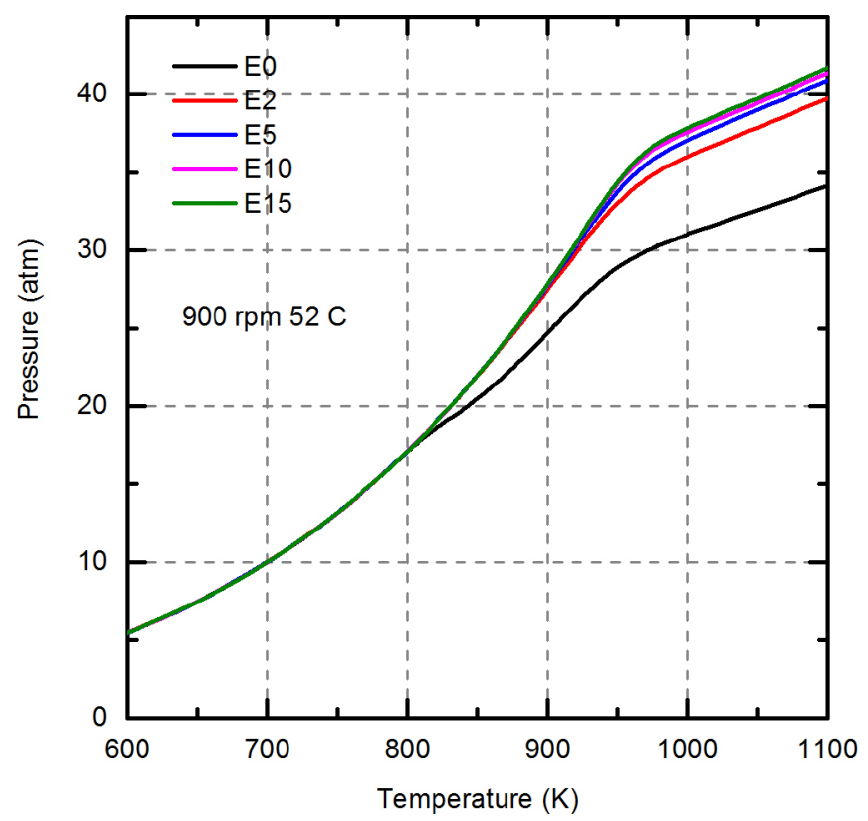

Figure 26. Simulated Pressure vs Temperature diagram for $900 \mathrm{rpm}$ and $52 \mathrm{C}$ (estimated $\mathrm{T}_{\mathrm{ivc}}$ 120C) case.

\section{Plotting the Pressure}

Temperature history of the reactions in an HCCI engine mode can give information about the physical requirements at the onset of low temperature reactions. Two changes in slope can be observed in each plots. They correspond to LTHR and HTHR onset. Temperature and pressure are related to each other by the polytropic index $(\gamma)$.

However, with the start of the reaction, the charge is a mixture of radicals and species, which changes the value of the index and hence the slope of T-P relation. This leads to change in slopes on the onset of LTC and later on HTC. The plots are provided in Figure 24, Figure $\underline{25}$, Figure 26, Figure 27 for the four cases considered previously. The assumption used in explaining fixed $\mathrm{T}_{3}$ value in discussing the role of LTHR phasing can also be validated from these figures. It is observed at the temperature at the onset of HTHR is, more or less, constant for same operating condition. Moreover, the onset of LTHR is seen to vary in both temperature and pressure with changing ethanol concentration. It can be seen in Figure 24, that LTHR onset happens at increasingly higher temperature with increasing ethanol concentration, which further corroborates the discussion above. Moreover, the magnitude can be analogous to the change in slope in these figures. It can be seen that ethanol (almost) completely suppresses the LTHR (and hence no change in slope around 700K). This can further be seen in Figure 28, which shows the same plot with maximum ethanol $\%(\mathrm{v} / \mathrm{v})$ considered in previous cases. This corresponds to $20 \%$ in $600 / 52$ and $600 / 149$ case, $15 \%$ in $900 / 52$ case and $10 \%$ in $900 / 149$ case. The values with addition of ethanol are given by dashed lines. This points to the efficacy of ethanol at LTHR suppression at different operating conditions.

It can be seen that even small quantity of ethanol is highly effective at reducing the magnitude of LTHR. At around 20\% ethanol (v/v), we find negligible LTHR, both in experiments and simulations. The effectiveness of ethanol in suppressing LTHR varies with speed and intake temperature. Complete suppression of LTHR happens at lower concentrations of ethanol when the intake temperature and engine speed are increased. The point of complete suppression of LTHR can be used as a design criteria to achieve higher benefits from ethanol addition. After LTHR has been fully suppressed (around 20\% in some cases), the addition of ethanol has almost linear effect on octane boosting, similar to addition of any high-octane (non-radicalscavenging) compound [15] (e.g., blending of iso-octane with n-heptane).

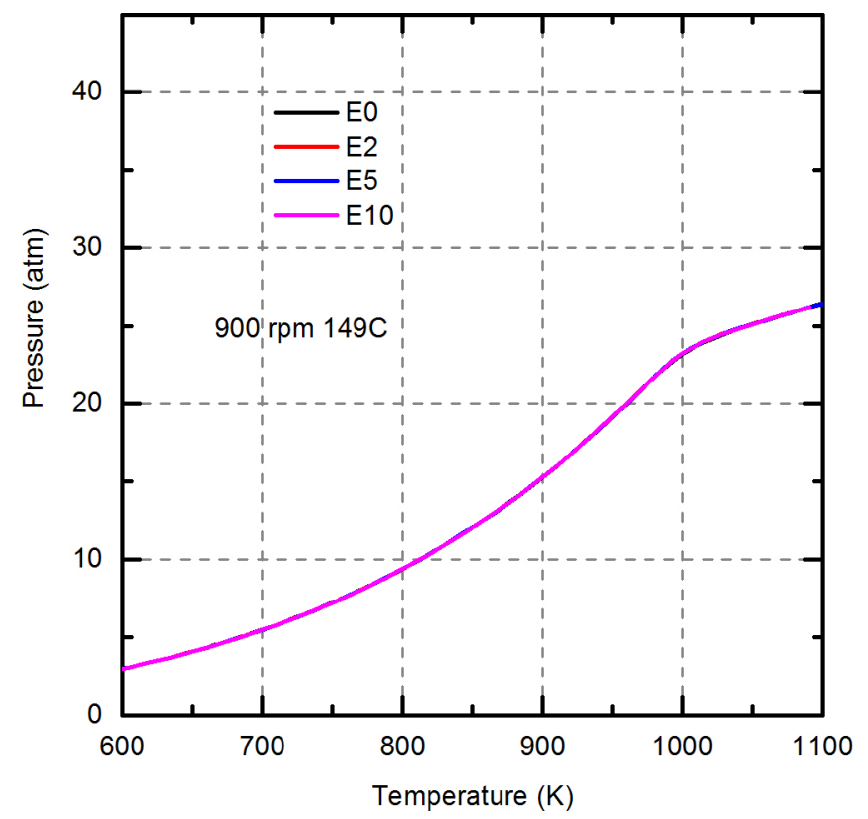

Figure 27. Simulated Pressure vs Temperature diagram for $900 \mathrm{rpm}$ and $149 \mathrm{C}$ (estimated $\mathrm{T}_{\mathrm{ivc}}$ 188C) case.

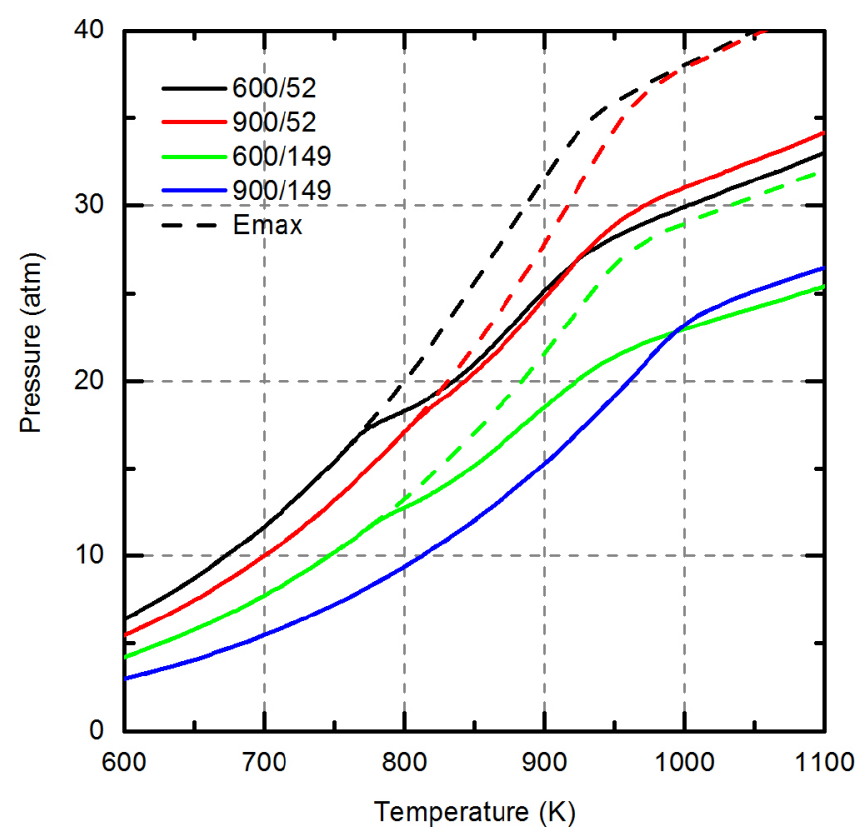

Figure 28. Simulated Pressure vs Temperature diagram for all the cases considered. Comparison for $\mathrm{E} 0$ to the maximum Ethanol \% (v/v) in each case.

\section{Conclusion}

This study provides insights into the kinetic reasoning behind the octane-boosting effect of ethanol addition to a primary reference fuel. Experiments conducted on a CFR engine were used as the base case for simulating same blends in single zone HCCI engine chemical kinetic solver. A thorough heat release analysis provided good insight into the effect of ethanol addition on LTHR. The following are the conclusions derived from the experiments and simulations. 
- Ethanol is a more effective octane booster at lower concentrations. Heat released during the low temperature chemistry region helped clarify the reason behind this nonlinearity of ethanol's effectiveness.

- Increasing Speed and intake temperature both have an inhibiting effect on the low temperature chemistry. Apart from inhibiting the low temperature chemistry, it gets further advanced with increasing intake temperature and speed.

- $\quad$ Ethanol is seen to suppress LTHR under all four conditions, and the effectiveness of ethanol reduced with increasing speed and intake temperature.

- Under all four conditions, ethanol drastically reduced the LTHR at $2 \%(\mathrm{v} / \mathrm{v})$. The release of less heat led to a lower increase in temperature, which further inhibited the autoignition of the mixture.

- The measure of $\mathrm{OH}$ and $\mathrm{HO}_{2}$ radicals in these regimes follows the LTHR, and confirms the radical scavenging nature of ethanol. The underlying competition between radical chain branching and radical chain termination reactions were discussed.

- The homogenous gas (single) phase simulations assured that physical effects did not contribute to LTHR suppression in our simulations (previously believed to be the major reason for the effectiveness of ethanol as an octane booster).

- $\quad$ Apart from the LTHR suppression, LTHR is phased differently with changing ethanol $\%(\mathrm{v} / \mathrm{v})$. LTHR is retarded with increasing ethanol concentration, which leads to higher temperature before the onset of HTHR, leading to poorer autoignition tendency (Figure 8 and $\underline{13}$ ).

The non-linearity in octane boosting tendency or HCCI number of ethanol stems from several factors: Firstly, at lower concentration, each ethanol (radical scavenger) sees more OH-producing molecules around it (nHeptane). Secondly, ethanol is highly effective in LTHR suppression, almost fully suppressed by $20 \%$ ethanol is most cases considered. Thereafter, the effect is nearly linear (similar to displacing a low octane fuel with a high octane fuel). Thirdly, addition of ethanol also retards the LTHR onset, leading to competing mechanism, with lower autoignition tendency from higher ethanol concentration. Overall, all these inter-related factors, simultaneously effect the autoignition tendency of the PRF70, lending the non-linear behavior.

\section{References}

1. Christensen, M., Johansson, B., and Einewall, P., "Homogeneous Charge Compression Ignition (HCCI) Using Isooctane, Ethanol and Natural Gas - A Comparison with Spark Ignition Operation," SAE Technical Paper 972874, 1997, doi: $10.4271 / 972874$.

2. Stanglmaier, R. and Roberts, C., "Homogeneous Charge Compression Ignition (HCCI): Benefits, Compromises, and Future Engine Applications," SAE Technical Paper 1999-013682, 1999, doi:10.4271/1999-01-3682.

3. Ishibashi, Y. and Sakuyama, H., "An Application Study of the Pneumatic Direct Injection Activated Radical Combustion TwoStroke Engine to Scooter," SAE Technical Paper 2004-01-1870, 2004, doi:10.4271/2004-01-1870.
4. Onishi, S., Jo, S., Shoda, K., Jo, P. et al., "Active ThermoAtmosphere Combustion (ATAC) - A New Combustion Process for Internal Combustion Engines," SAE Technical Paper 790501, 1979, doi:10.4271/790501.

5. Hardenberg, Horst "Samuel Morey and His Atmospheric Engine," (Warrendale, Society of Automotive Engineers, Inc., 1992), 6-7, ISBN:1560912405.

6. Farrell Gabriel Jr., "Capt. Samuel Morey who built a Steaboat fourteen years before Fulton," Granite State Magazine 12 (1911): 93.

7. Mowry WM. A., Who invented the American Steamboat? (Bristol: New Hampshire Antiquarian Society, 1874) 22-23.

8. Goodwin Katherine R. and Duryea Charles E., "Samuel Morey, Precursor of Motor Power Development," The Vermonter 36 (1931): 141-2.

9. Egloff, G., Morrell, J.C., "Alcohol-Gasoline as Motor Fuels," Symposium on Motor Fuels, June 1936, Universal Oil Product Company. Ind. Eng. Chem., 1936, 28 (9), pp 1080-1088, doi: $10.1021 /$ ie $50321 \mathrm{a} 024$

10. Oakley, A., Zhao, H., Ladommatos, N., and Ma, T., "Dilution Effects on the Controlled Auto-Ignition (CAI) Combustion of Hydrocarbon and Alcohol Fuels," SAE Technical Paper 200101-3606, 2001, doi:10.4271/2001-01-3606.

11. Lichty, L.C., E.J. Ziurys, E.J. "Engine performance with gasoline and alcohol, 1936," Yale University, New Haven, CN. Industrial and Engineering Chemistry, Sept 1936. Ind. Eng. Chem., 1936, 28 (9), pp 1094-1101, doi: 10.1021/ie50321a026

12. Lichty, Lester Clyde, and Phelps Charles Worthington. "Gasoline-alcohol blends in internal combustion engines." Industrial \& Engineering Chemistry 30, no. 2 (1938): 222230. Ind. Eng. Chem., 1938, 30 (2), pp 222-230, doi:10.1021/ ie50338a023

13. Puckett, A.D., "Knock Rating of Gasoline Substitutes," RP1763, Journal of Research of National Bureau of Standards, Volume 35, Oct 1945.

14. Porter, J.C., Weibe, R., "Alcohol as an Antiknock Agent in Automotive Applications," Northern Regional Research Laboratory. Peoria. IL. Ind. Eng. Chem., 1952, 44 (5), pp 10981104, doi: $\underline{10.1021 / i e 50509 a 048}$

15. Anderson, J., Leone, T., Shelby, M., Wallington, T. et al., "Octane Numbers of Ethanol-Gasoline Blends: Measurements and Novel Estimation Method from Molar Composition," SAE Technical Paper 2012-01-1274, 2012, doi:10.4271/2012-01-1274.

16. American Petroleum Institute (API) "Determination of the potential property ranges of mid-level ethanol blends: final report," Tech. Rep.; 2010. <http://www.api.org//media/Files/ Policy/Alternatives/E10-Blending-Study-Final-Report.pdf $>$.

17. Foong, T.M., Morganti, K.J., Brear, M.J., da Silva, G., Yang, Y., Dryer, F.L. "The octane numbers of ethanol blended with gasoline and its surrogates." Fuel 115 (2014): 727-739. http:// dx.doi.org/10.1016/j.fuel.2013.07.105

18. Kalghatgi, G., Risberg, P., and Ångstrom, H., "A Method of Defining Ignition Quality of Fuels in HCCI Engines," SAE Technical Paper 2003-01-1816, 2003, doi:10.4271/2003-01-1816. 
19. Kalghatgi, G., "Auto-Ignition Quality of Practical Fuels and Implications for Fuel Requirements of Future SI and HCCI Engines," SAE Technical Paper 2005-01-0239, 2005, doi: 10.4271/2005-01-0239.

20. Risberg, P., Kalghatgi, G., and Ångstrom, H., "Auto-ignition Quality of Gasoline-Like Fuels in HCCI Engines," SAE Technical Paper 2003-01-3215, 2003, doi: 10.4271/2003-01-3215.

21. Kalghatgi, G. and Head, R., "The Available and Required Autoignition Quality of Gasoline - Like Fuels in HCCI Engines at High Temperatures," SAE Technical Paper 2004-01-1969, 2004, doi:10.4271/2004-01-1969.

22. Shibata, G. and Urushihara, T., "Auto-Ignition Characteristics of Hydrocarbons and Development of HCCI Fuel Index," SAE Technical Paper 2007-01-0220, 2007, doi:10.4271/2007-01-0220.

23. Shibata, G., Oyama, K., Urushihara, T., and Nakano, T., "Correlation of Low Temperature Heat Release With Fuel Composition and HCCI Engine Combustion," SAE Technical Paper 2005-01-0138, 2005, doi:10.4271/2005-01-0138.

24. Truedsson, I., Cannella, W., Johansson, B., and Tuner, M., "Development of New Test Method for Evaluating HCCI Fuel Performance," SAE Technical Paper 2014-01-2667, 2014, doi: $10.4271 / 2014-01-2667$.

25. ASTM STP 225

26. Waqas, M., Naser, N., Sarathy, M., Morganti, K. et al., "Blending Octane Number of Ethanol in HCCI, SI and CI Combustion Modes," SAE Int. J. Fuels Lubr. 9(3):659-682, 2016, doi:10.4271/2016-01-2298.

27. Kelly-Zion, P.L., Dec, J., “A computational study of effect of fuel type on ignition time in HCCI engines," 28th Symposium (International) on Combustion, Combustion Institute, 2000. http://dx.doi.org/10.1016/S0082-0784(00)80329-X.

28. Kong, S., Marriott, C., Reitz, R., and Christensen, M., "Modeling and Experiments of HCCI Engine Combustion Using Detailed Chemical Kinetics with Multidimensional CFD," SAE Technical Paper 2001-01-1026, 2001, doi:10.4271/2001-01-1026.

29. Kong, S, C., Reitz, R.D., "Use of Detailed Chemical Kinetics to Study HCCI Engine Combustion with Consideration of Turbulent Mixing Effects," ASME. Journal of Engineering Gas Turbines Power, 2002;124(3):702-707. doi:10.1115/1.1413766.

30. Dec, J. and Sjöberg, M., "Isolating the Effects of Fuel Chemistry on Combustion Phasing in an HCCI Engine and the Potential of Fuel Stratification for Ignition Control," SAE Technical Paper 2004-01-0557, 2004, doi:10.4271/2004-01-0557.

31. Frassoldati A., Cuoci A., Faravelli T., and Ranzi E., "Kinetic modeling of the oxidation of ethanol and gasoline surrogate mixtures", Combust. Sci. and Tech., 182: 653-667, 2010. doi: $\underline{10.1080 / 00102200903466368}$

32. Fikri, M., Herzler, J., Starke, R., Shulz, C., Roth, P., and Kalghatgi, G.T. 2008. "Autoignition of gasoline surrogates mixtures at intermediate temperatures and high pressures." Comb. Flame, 152, 276-281. doi:10.1016/j. combustflame.2007.07.010

33. Sarathy, S.M., Osswald, P., Hansen, N., Kohse-Höeinghaus, K., "Alcohol combustion chemistry," Progress in Energy and Combustion Science. 44 (2014) 40-102. doi:10.1016/j. pecs.2014.04.003.
34. Vuilleumier, D., Selim, H., Dibble, R., and Sarathy, M., "Exploration of Heat Release in a Homogeneous Charge Compression Ignition Engine with Primary Reference Fuels," SAE Technical Paper 2013-01-2622, 2013, doi:10.4271/2013-01-2622.

35. Vuilleumier, D., Kozarac, D., Mehl et al., "Intermediate temperature heat release in an HCCI engine fueled by ethanol/nheptane mixtures: an experimental and modeling study," Combustion and Flame 161 (3) (2014) 680-695. doi:10.1016/j. combustflame.2013.10.008

36. Shankar, V. S. B., Al-Abbad, M., El-Rachidi, M., "Antiknock quality and ignition kinetics of 2-phenylethanol, a novel lignocellulosic octane booster." Proceedings of the Combustion Institute (2016). doi: 10.1016/j.proci.2016.05.041

37. Chang, J., Viollet, Y., Alzubail, A., Abdul-Manan, A. et al., "Octane-on-Demand as an Enabler for Highly Efficient Spark Ignition Engines and Greenhouse Gas Emissions Improvement," SAE Technical Paper 2015-01-1264, 2015, doi:10.4271/201501-1264.

38. Viollet, Y., Abdullah, M., Alhajhouje, A., and Chang, J., "Characterization of High Efficiency Octane-On-Demand Fuels Requirement in a Modern Spark Ignition Engine with Dual Injection System," SAE Technical Paper 2015-01-1265, 2015, doi: 10.4271/2015-01-1265.

39. Kee, R.J., Rupley, F.M., Miller J.A., "Chemkin II- a FORTRAN Chemical Kinetics Package for the analysis of Gas Phase Chemical Kinetics," Sandia Report, SAND 89-8009, 1989.

40. Mehl, M.; Pitz, W. J.; Westbrook, C. K.; Curran, H. J. "Kinetic modeling of gasoline surrogate components and mixtures under engine conditions," Proc Combust Inst 2011;33:193-200. doi:10.1016/j.proci.2010.05.027

41. Zhou, C. W., Li, Y., O'Connor, E. et al. "A comprehensive experimental and modeling study of isobutene oxidation", Combustion and Flame 167 (2016) 353-379. doi:10.1016/j. combustflame.2016.01.021

42. Atef, N., Kukkadapu, G., Mohamed, S. Y. et al "A comprehensive iso-octane combustion model with improved thermochemistry and chemical kinetics", Accepted to Combustion and Flame, Dec 2016.

43. Merchant, S. S., Goldsmith, C. F., Vandeputte, A. G. et al. "Understanding low-temperature first-stage ignition delay: Propane," Combustion and Flame, 162, 2015, 3658-3673. doi:10.1016/j.combustflame.2015.07.005

44. Lapuerta, M. N., Hernańdez, J. J., Sarathy, S. M., "Effects of methyl substitution on the auto-ignition of C16 alkanes," Combustion and Flame, 164, 2016, 259-269. doi: 10.1016/j. combustflame.2015.11.024

45. Westbrook C., "Oxidation and combustion of the n-hexene isomers: A wide range kinetic modeling study," Proc. Combust Inst, 2000, pp. 1563-1577. doi: 10.1016/j. combustflame.2008.07.004

46. Aronsson, U., Solaka, H., Lequien, G., Andersson, O. et al., "Analysis of Errors in Heat Release Calculations Due to Distortion of the In-Cylinder Volume Trace from Mechanical Deformation in Optical Diesel Engines," SAE Int. J. Engines 5(4):1561-1570, 2012, doi:10.4271/2012-01-1604. 
47. Hwang, W., Dec, J., Sjoberg, M., "Spectroscopic and ChemicalKinetic Analysis of the Phases of HCCI Autoignition and Combustion for Single- and Two-Stage Ignition Fuels," Combustion and Flame, 154(3): 387-409, 2008. doi:10.1016/j. combustflame.2008.03.019

48. Truedsson I, Tuner M, Johansson B, Cannella W., "Pressure Sensitivity of HCCI Auto-Ignition Temperature for Oxygenated Reference Fuels," ASME Journal of Engineering for Gas Turbines and Power, 2013;135(7):072801-072801-13. doi: $10.1115 / 1.4023614$.

49. Sjöberg, M. and Dec, J., "An Investigation of the Relationship Between Measured Intake Temperature, BDC Temperature, and Combustion Phasing for Premixed and DI HCCI Engines," SAE Technical Paper 2004-01-1900, 2004, doi:10.4271/2004-01-1900.

50. Sjöberg, M. and Dec, J., "Combined Effects of Fuel-Type and Engine Speed on Intake Temperature Requirements and Completeness of Bulk-Gas Reactions for HCCI Combustion," SAE Technical Paper 2003-01-3173, 2003, doi:10.4271/200301-3173.

51. Dec, J., Yang, Y., Dernotte, J., and Ji, C., "Effects of Gasoline Reactivity and Ethanol Content on Boosted, Premixed and Partially Stratified Low-Temperature Gasoline Combustion (LTGC)," SAE Int. J. Engines 8(3):935-955, 2015, doi:10.4271/2015-01-0813.

52. Zhu, S.W., Wang, C.M., Qian, Y.J., Ou, L.J., Wang, H.C., "Numerical Simulation of the Effect of Ethanol on Diesel HCCI Combustion using Multi-Zone Model," Applied Mechanics and Materials, Vols. 229-231, pp. 78-81, 2012. doi:10.4028/www. scientific.net/AMM.229-231.78

53. Sarathy, S.M., Kukkadapu, G., Mehl, M., Wang, W., Mehl, M., Wang, W., Javed, T., Park, S., Oehlschlaeger, M.A., Farooq, A., Pitz, W.J., Sung, C.-J., "Ignition of alkane rich FACE gasoline fuels," Proc. Combust. Inst. 35 (2015) 249-257. doi:10.1016/j. proci.2014.05.122

54. Kukkadapu, G., Kumar, K., Sung, C.-J., Mehl, M., Pitz, W.J., "Autoignition of gasoline and its surrogates in a rapid compression machine," Proc. Combust. Inst. 34 (2013) 345-352. doi: 10.1016/j.proci.2012.06.135

55. Shen, H.-P.S., Steinberg, J., Vanderover, J., Oehlschlaeger, M.A., "A shock tube study of the ignition of n-heptane, n-decane, n-dodecane, and n-tetradecane at elevated pressures," Energy Fuels, 23 (2009) 2482-2489. doi: 10.1021/ef8011036
56. Sarathy, S. M., Westbrook, C., Mehl, M. et al. "Comprehensive chemical kinetic modeling of the oxidation of 2-methylalkanes from C7 to C20," Combustion and Flame 1148158 (2011) 2338-2357. 1149. doi: 10.1016/j.combustflame.2011.05.007

57. Mohamed, S.Y., Cai, L., Khaled, F. et al. "Modeling ignition of a heptane isomer: improved thermodynamics, reaction pathways, kinetics, and rate rule optimizations for 2-methylhexane," J. Phys. Chem. A, 2016, 120 (14), pp 22012217. doi:10.1021/acs.jpca.6b00907

58. Wang, Z., Sarathy, S.M., "Third O2 addition reactions promote the low- temperature auto-ignition of n-alkanes," Combustion and Flame, 165 (2016) 364-372. doi:10.1016/j. combustflame.2015.12.020

59. Zhang, P., Ji, W., He, T, He, X., Wang, Z., Yang, B., Law, C. K. "First-stage ignition delay in the negative temperature coefficient behavior: Experiment and simulation," Combustion and Flame, 2016, 1-10. http://doi.org/10.1016/j. combustflame.2016.03.002

60. Zádor, J., Taatjes, C. A., Fernandes, R. X., "Kinetics of elementary reactions in low-temperature autoignition chemistry," Progress in Energy and Combustion Science, 2011, 37(4), 371-421. doi: 10.1016/j.pecs.2010.06.006

61. Curran, H., Gaffuri, P., Pitz, W., Westbrook, C., “A comprehensive modeling study of n-heptane oxidation," Combustion and Flame, 1998, 114(1-2), 149-177. doi:10.1016/ $\underline{\text { S0010-2180(97)00282-4 }}$

62. Curran, H., Gaffuri, P., Pitz, W., Westbrook, C. A. "Comprehensive modeling study of iso-octane oxidation," Combustion and Flame, 2002, 129(3), 253-280. doi:10.1016/ S0010-2180(01)00373-X

\section{Definitions/Abbreviations}

RPM - Revolutions per minute

CAD - Crank angle degree

CA50 - Crank angle for 50\% heat release

PRF - Primary reference fuel

E - Ethanol

TDC - Top Dead Center

aTDC - After Top Dead Center 


\section{$\underline{\text { APPENDIX }}$}

\section{APPENDIX 1: HEAT RELEASE ANALYSIS}

First law heat release can be given by:

$$
{\frac{d Q}{d \theta_{1 s t}}}=\frac{\gamma}{\gamma-1} \frac{P d V}{d \theta}+\frac{1}{\gamma-1} \frac{V d P}{d \theta}
$$

By adding the heat losses from different sources, the net heat released is attained. Heat transfer to the walls is based on the Woschini analysis [1] It is given by:

$$
h=131 \times(\text { Bore })^{-0.2} \times P^{0.8} \times T^{-0.55} w^{0.8}
$$

where

$$
w=C_{1} \times 2.28 \times S_{p}+C_{2} \times 3.24 \times 10^{-3} \times \frac{V_{d}}{V_{I V C}} \times\left(\frac{P_{f i r}-P_{m o t}}{P_{I V C}}\right) \times T_{I V C}
$$

From these comes:

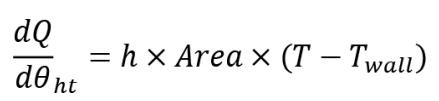

Crevices are high surface area/volume regions, hence heat loss depends on pressure, as well as temperature history. The crevice volume varies between $1 \%-5 \%$ of the compression volume, typically []ㅡ.

$$
\frac{d Q}{d \theta_{c r}}=V_{\text {crevice }} \times d P \times\left(\frac{T_{p}}{T_{\text {wall }}}+\frac{T_{i}}{(\gamma-1) T_{\text {wall }}}+\frac{1}{10^{-5} \gamma} \log \left(\frac{\gamma-1}{\gamma_{p}-1}\right)\right)
$$

Where $T_{p}$ and $\gamma_{p}$ are equal to $T$ and $\gamma$ respectively, during compression and during power stroke they are given by:

$$
\begin{gathered}
T_{p}=T_{\text {wall }} \\
\gamma_{p}=1.4-\frac{8.3}{100}\left(\frac{T_{\text {wall }}-300}{1000}\right)
\end{gathered}
$$

Losses occurring from blow-by area []ㅡ are dependent on pressure inside the chamber and are given by:

$$
{\frac{d Q}{d \theta_{b b}}}_{b \times \text { Area }_{b b} \times 0.001}
$$

The net heat released in a cycle is the sum of the considered values:

$$
\frac{d Q}{d \theta}={\frac{d Q}{d \theta_{1 s t}}}_{1 \theta_{h t}}+{\frac{d Q}{d \theta_{c r}}}+{\frac{d Q}{d \theta_{b b}}}
$$

The constants were chosen so that the net heat released during a motoring cycle was zero. An optimization program that provided the values of these constants was run to yield the optimal heat release analysis. Once these values were fixed, the code was run for combustion cases, and heat release was calculated from the firing cycles.

1. Woschni, G., "A Universally Applicable Equation for the Instantaneous Heat Transfer Coefficient in the Internal Combustion Engine," SAE Technical Paper 670931, 1967, doi:10.4271/670931.

2. Gatowski, J., Balles, E., Chun, K., Nelson, F. et al., "Heat Release Analysis of Engine Pressure Data," SAE Technical Paper 841359, 1984, doi:10.4271/841359.

3. Hohenberg, G., "Advanced Approaches for Heat Transfer Calculations," SAE Technical Paper 790825, 1979, doi: 10.4271/790825. 
APPENDIX 2: MATCHING HEAT RELEASE RATE FROM EXPERIMENTS AND SIMULATION (CRITERIA 10J/DEG)

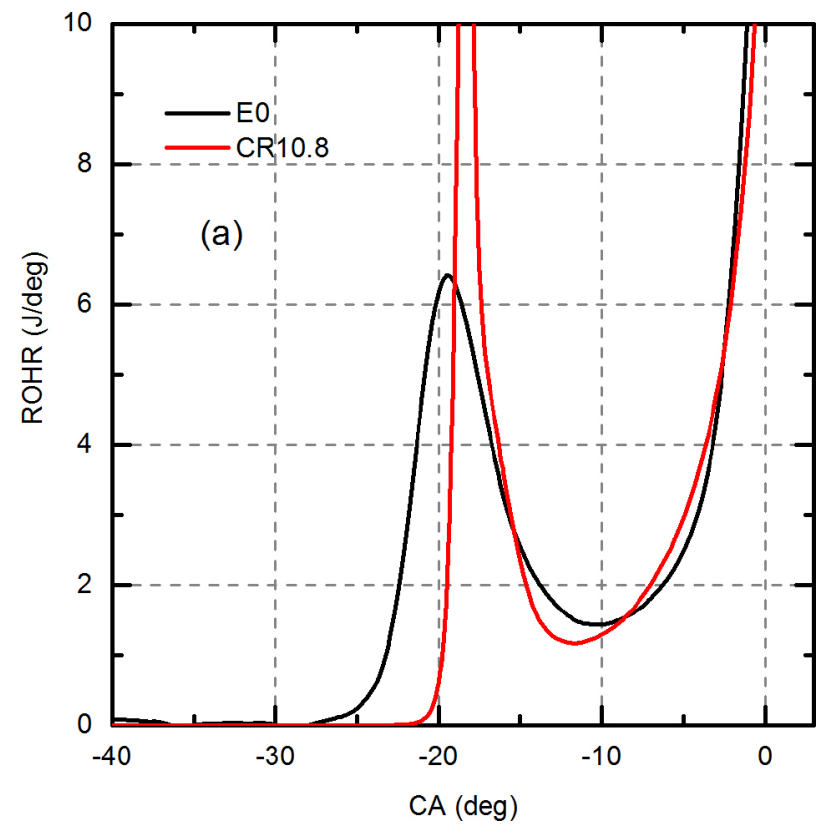

Figure A1a. Experimental (black) and simulated (red) rate of heat release for PRF70. Compression ratio used in simulation is given in legend. $600 \mathrm{rpm}$

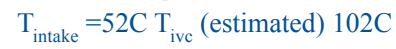

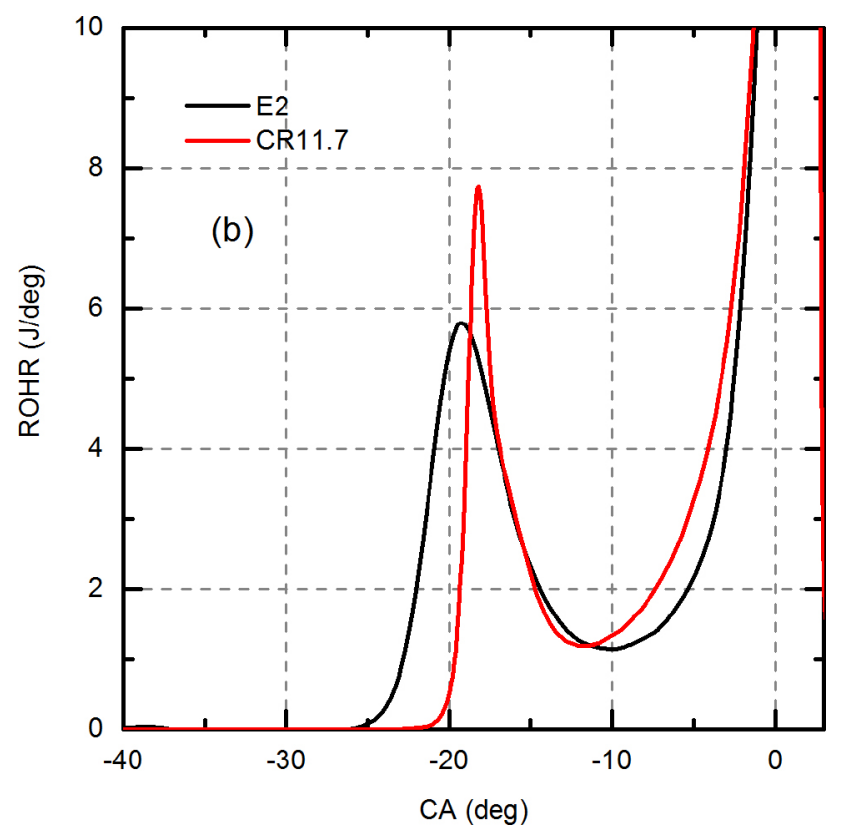

Figure A1b. Experimental (black) and simulated (red) rate of heat release for PRF70E2. Compression ratio used in simulation is given in legend. $600 \mathrm{rpm}$ $\mathrm{T}_{\text {intake }}=52 \mathrm{C} \mathrm{T}_{\mathrm{ivc}}$ (estimated) $102 \mathrm{C}$ 


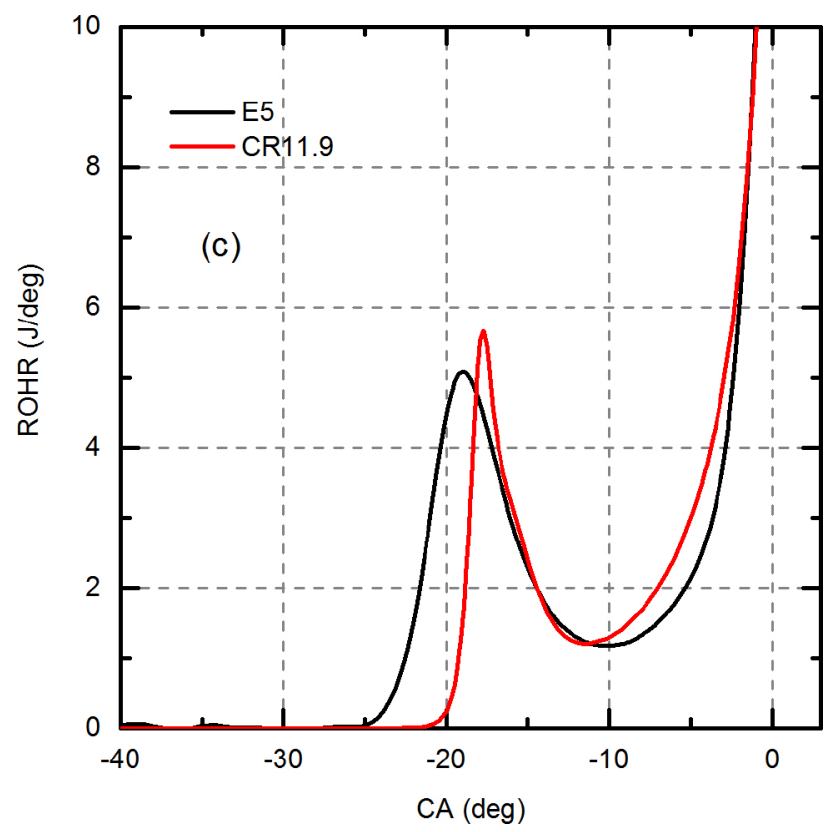

Figure A1c. Experimental (black) and simulated (red) rate of heat release for PRF70E5. Compression ratio used in simulation is given in legend. $600 \mathrm{rpm}$ $\mathrm{T}_{\text {intake }}=52 \mathrm{C} \mathrm{T}_{\mathrm{ivc}}$ (estimated) $102 \mathrm{C}$

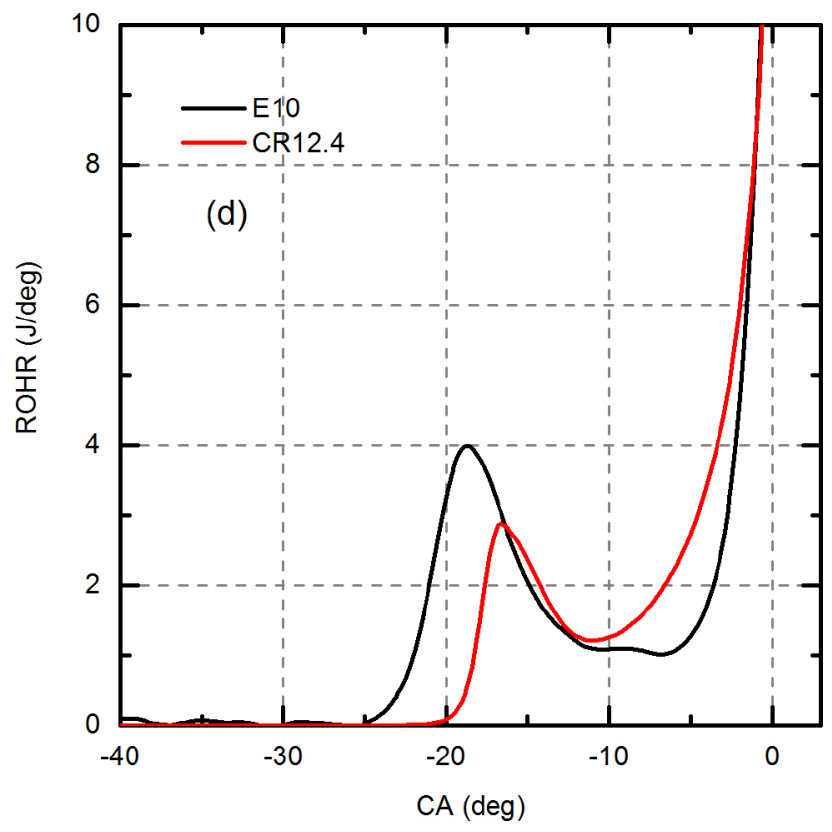

Figure A1d. Experimental (black) and simulated (red) rate of heat release for PRF70E10. Compression ratio used in simulation is given in legend. $600 \mathrm{rpm}$ $\mathrm{T}_{\text {intake }}=52 \mathrm{C} \mathrm{T}_{\text {ivc }}$ (estimated) $102 \mathrm{C}$ 


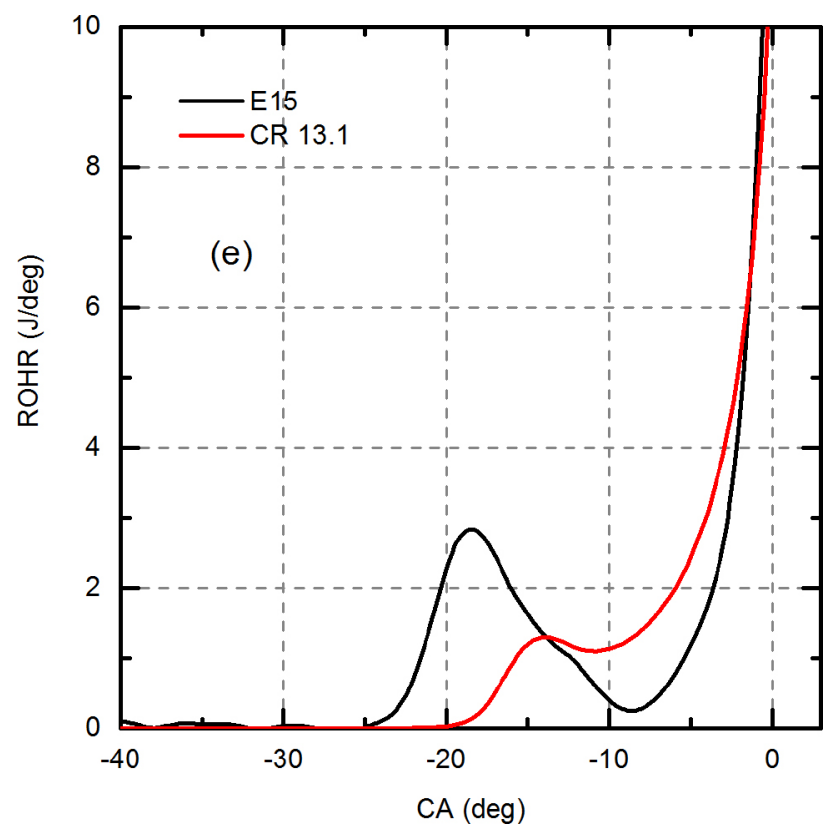

Figure A1e. Experimental (black) and simulated (red) rate of heat release for PRF70E15. Compression ratio used in simulation is given in legend. $600 \mathrm{rpm}$ $\mathrm{T}_{\text {intake }}=52 \mathrm{C} \mathrm{T}_{\mathrm{ivc}}$ (estimated) $102 \mathrm{C}$

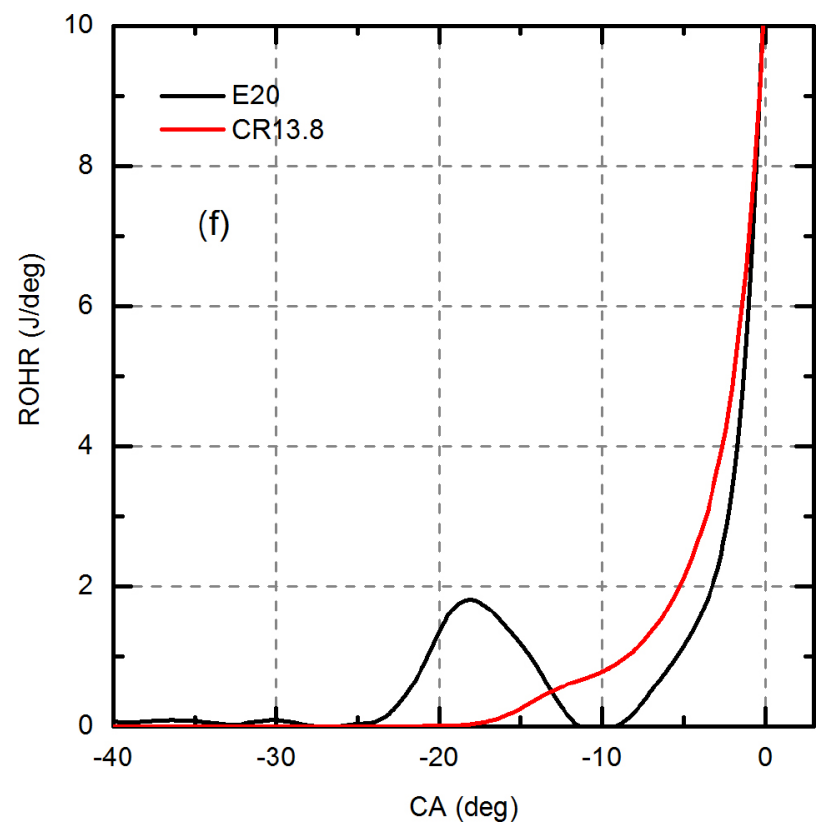

Figure A1f. Experimental (black) and simulated (red) rate of heat release for PRF70E20. Compression ratio used in simulation is given in legend. $600 \mathrm{rpm}$ $\mathrm{T}_{\text {intake }}=52 \mathrm{C} \mathrm{T}_{\mathrm{ivc}}$ (estimated) $102 \mathrm{C}$. 


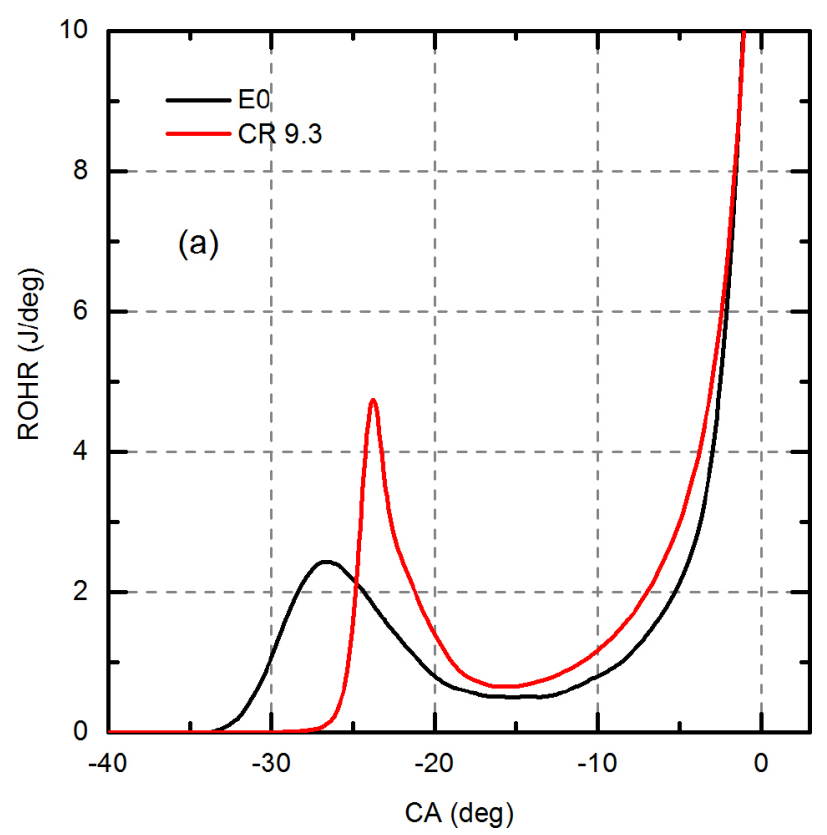

Figure A2a. Experimental (black) and simulated (red) rate of heat release for PRF70. Compression ratio used in simulation is given in legend. $600 \mathrm{rpm}$ $\mathrm{T}_{\text {intake }}=149 \mathrm{C} \mathrm{T}_{\mathrm{ivc}}$ (estimated) $146 \mathrm{C}$.

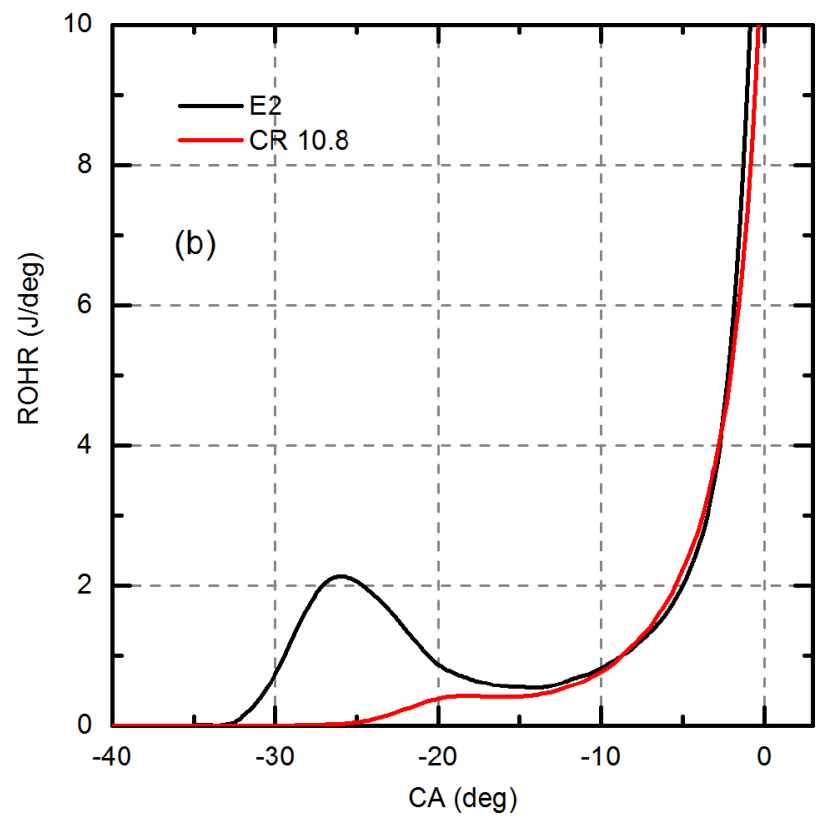

Figure A2b. Experimental (black) and simulated (red) rate of heat release for PRF70E2. Compression ratio used in simulation is given in legend. $600 \mathrm{rpm}$ $\mathrm{T}_{\text {intake }}=149 \mathrm{C} \mathrm{T}_{\mathrm{ivc}}$ (estimated) $146 \mathrm{C}$. 


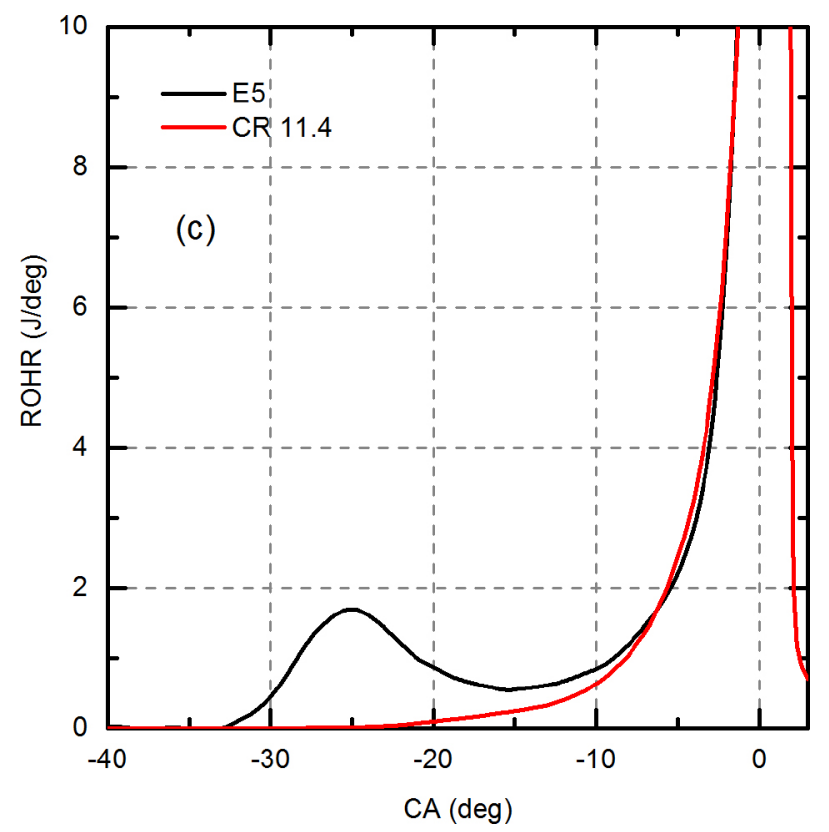

Figure A2c. Experimental (black) and simulated (red) rate of heat release for PRF70E5. Compression ratio used in simulation is given in legend. $600 \mathrm{rpm}$ $\mathrm{T}_{\text {intake }}=149 \mathrm{C} \mathrm{T}_{\mathrm{ivc}}$ (estimated) $146 \mathrm{C}$.

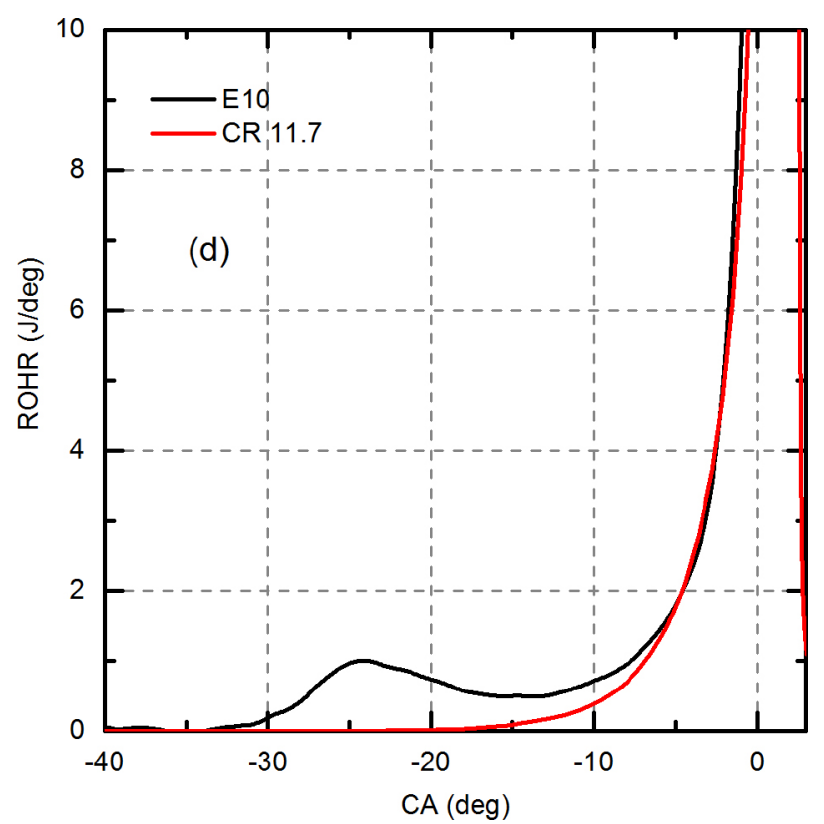

Figure A2d. Experimental (black) and simulated (red) rate of heat release for PRF70E10. Compression ratio used in simulation is given in legend. $600 \mathrm{rpm}$ $\mathrm{T}_{\text {intake }}=149 \mathrm{C} \mathrm{T}_{\text {ivc }}$ (estimated) $146 \mathrm{C}$. 


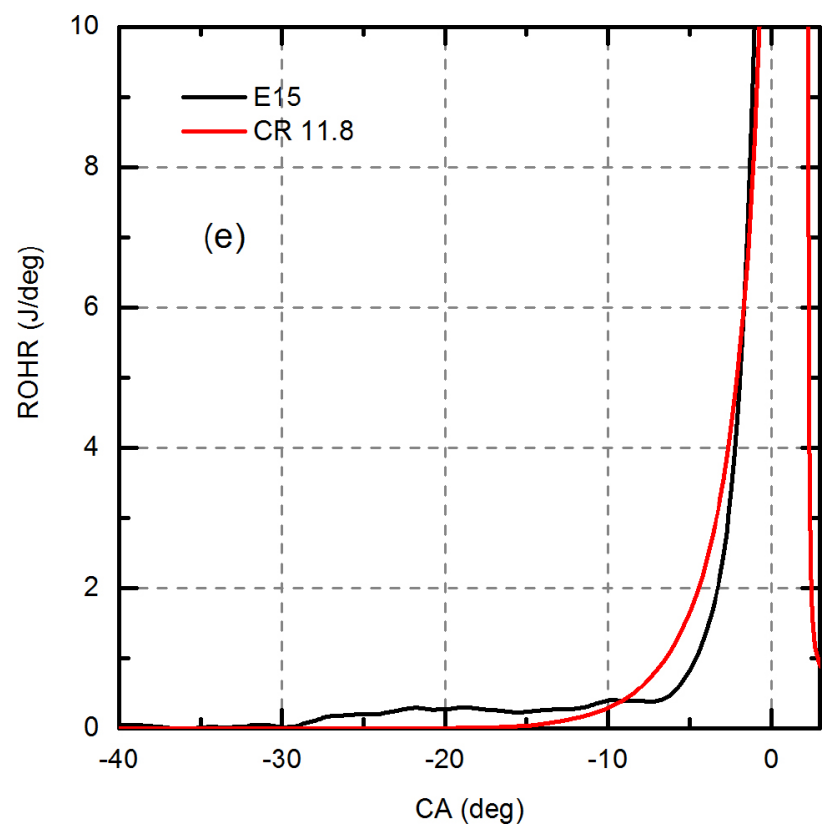

Figure A2e. Experimental (black) and simulated (red) rate of heat release for PRF70E15. Compression ratio used in simulation is given in legend. $600 \mathrm{rpm}$ $\mathrm{T}_{\text {intake }}=149 \mathrm{C} \mathrm{T}_{\mathrm{ivc}}$ (estimated) $146 \mathrm{C}$.

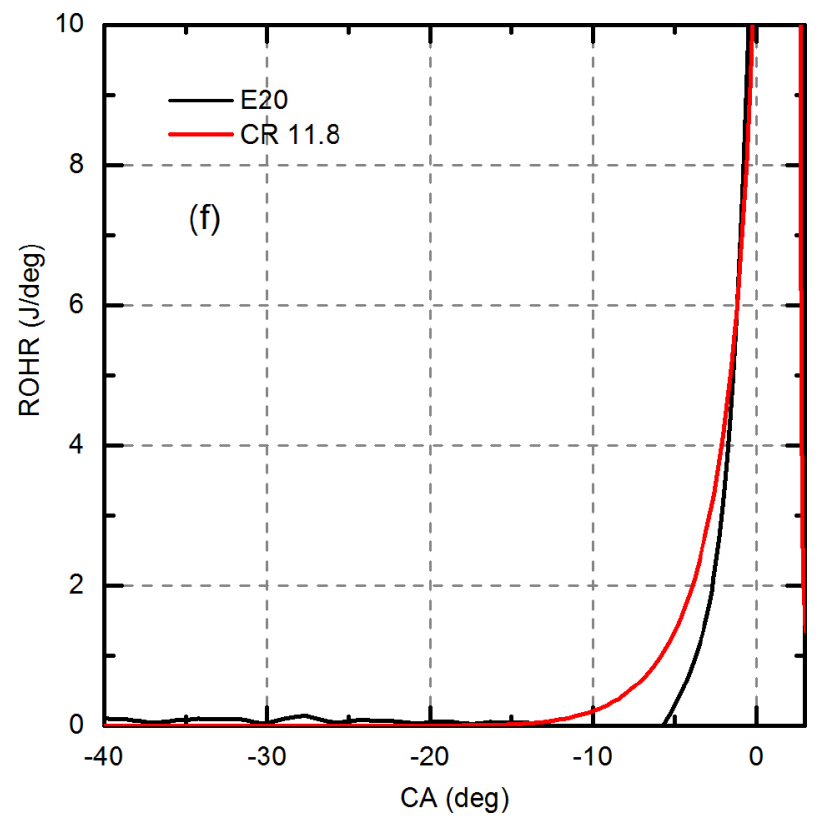

Figure A2f. Experimental (black) and simulated (red) rate of heat release for PRF70E20. Compression ratio used in simulation is given in legend. $600 \mathrm{rpm}$ $\mathrm{T}_{\text {intake }}=149 \mathrm{C} \mathrm{T}_{\mathrm{ivc}}$ (estimated) $146 \mathrm{C}$. 


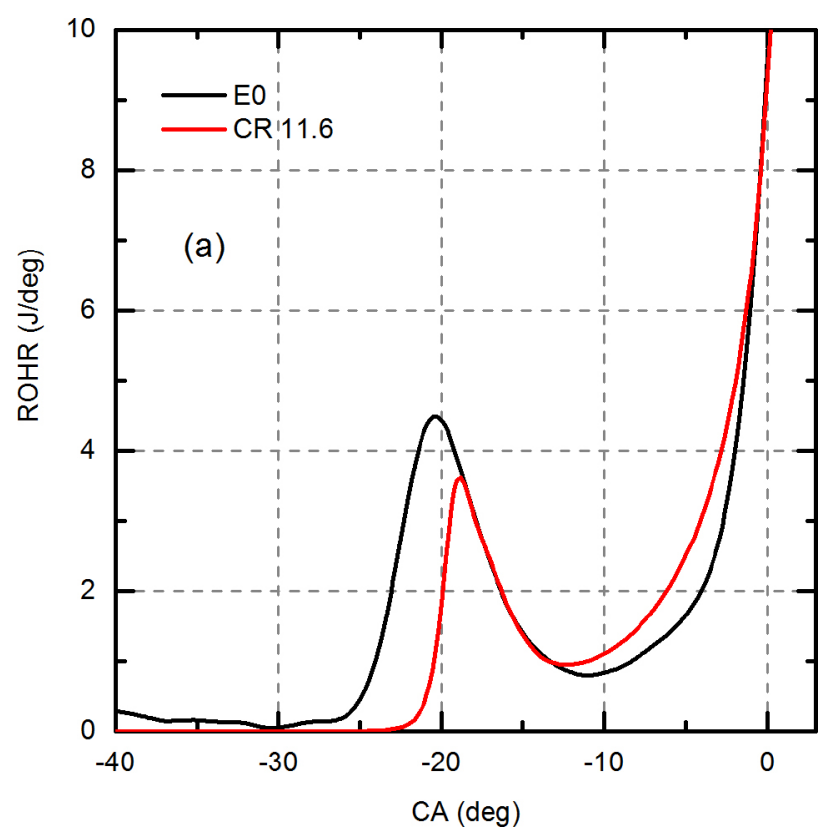

Figure A3a. Experimental (black) and simulated (red) rate of heat release for PRF70. Compression ratio used in simulation is given in legend. $900 \mathrm{rpm}$ $\mathrm{T}_{\text {intake }}=52 \mathrm{C} \mathrm{T}_{\mathrm{ivc}}$ (estimated) $120 \mathrm{C}$.

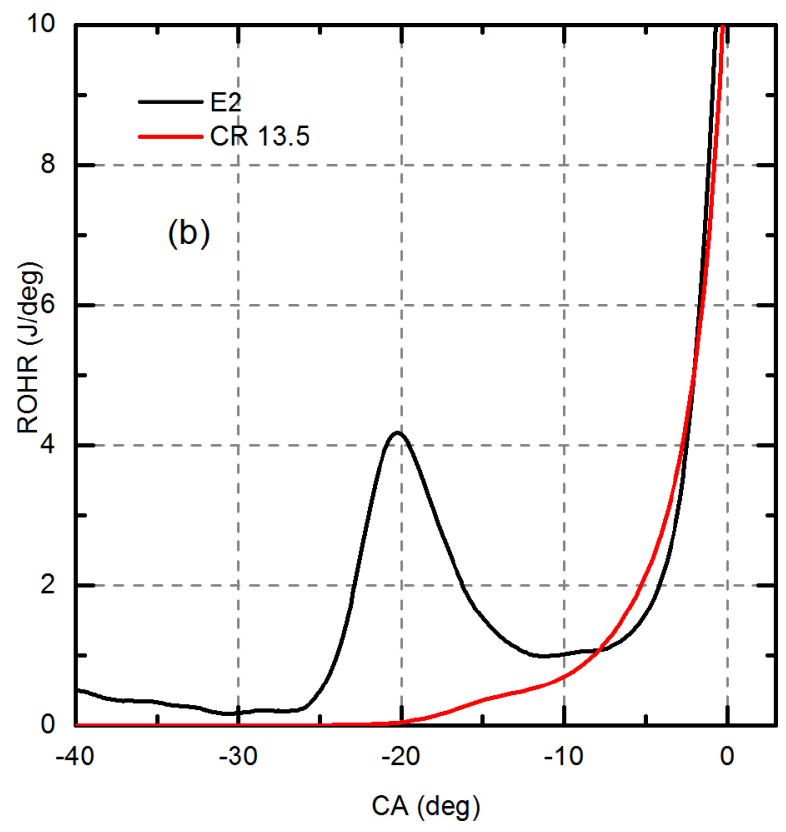

Figure A3b. Experimental (black) and simulated (red) rate of heat release for PRF70E2. Compression ratio used in simulation is given in legend. $900 \mathrm{rpm}$ $\mathrm{T}_{\text {intake }}=52 \mathrm{C} \mathrm{T}_{\text {ivc }}$ (estimated) $120 \mathrm{C}$. 


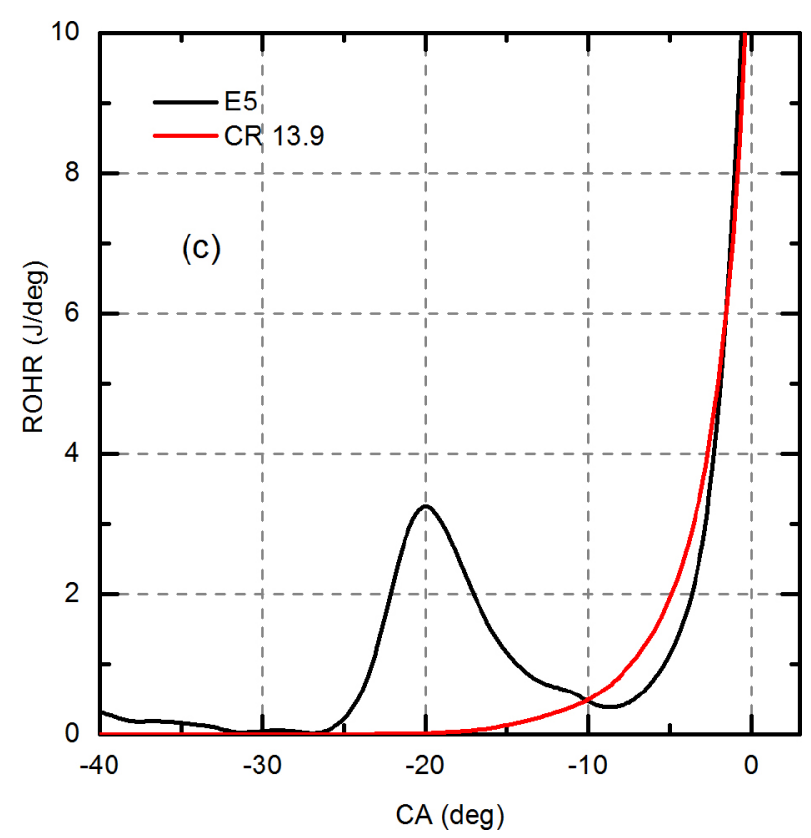

Figure A3c. Experimental (black) and simulated (red) rate of heat release for PRF70E5. Compression ratio used in simulation is given in legend. $900 \mathrm{rpm}$ $\mathrm{T}_{\text {intake }}=52 \mathrm{C} \mathrm{T}_{\mathrm{ivc}}$ (estimated) $120 \mathrm{C}$.

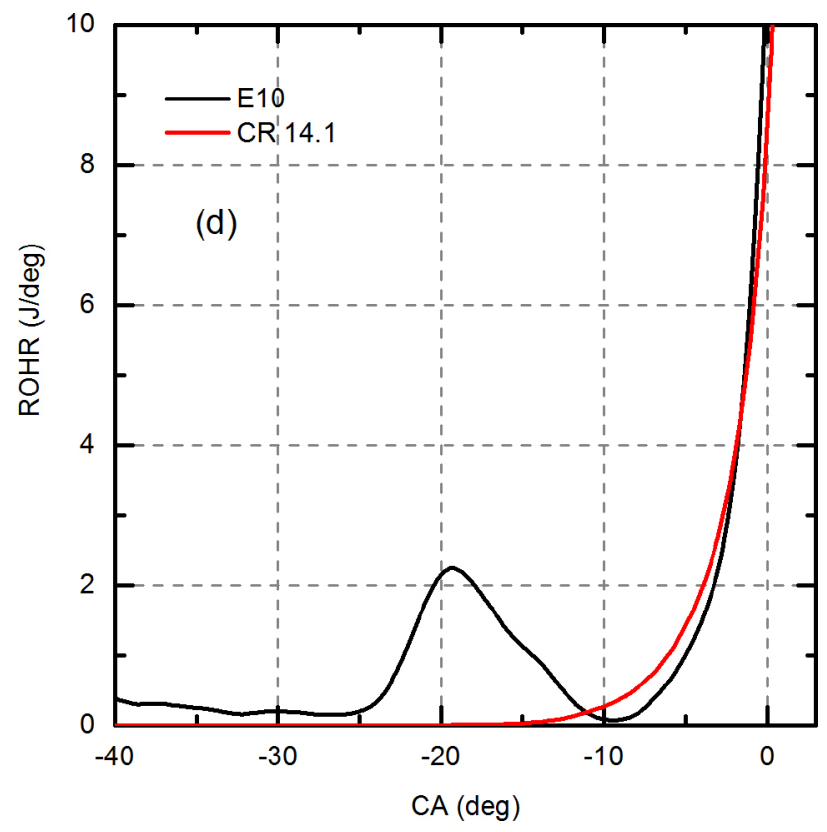

Figure A3d. Experimental (black) and simulated (red) rate of heat release for PRF70E10. Compression ratio used in simulation is given in legend. $900 \mathrm{rpm}$ $\mathrm{T}_{\text {intake }}=52 \mathrm{C} \mathrm{T}_{\mathrm{ivc}}$ (estimated) $120 \mathrm{C}$. 


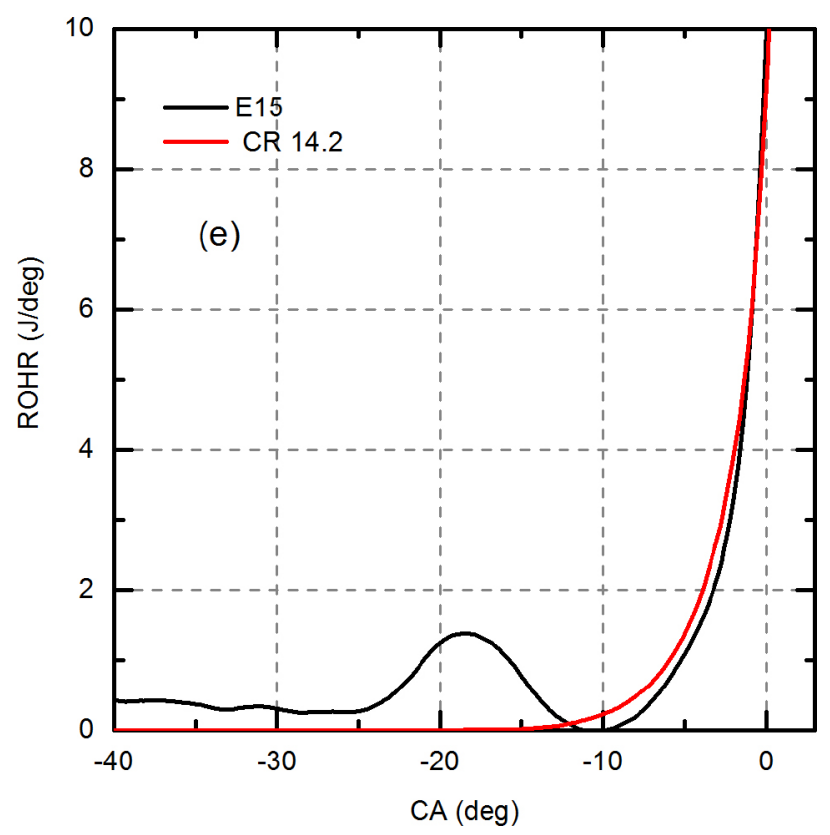

Figure A3e. Experimental (black) and simulated (red) rate of heat release for PRF70E15. Compression ratio used in simulation is given in legend. $900 \mathrm{rpm}$ $\mathrm{T}_{\text {intake }}=52 \mathrm{C} \mathrm{T}_{\mathrm{ivc}}$ (estimated) $120 \mathrm{C}$.

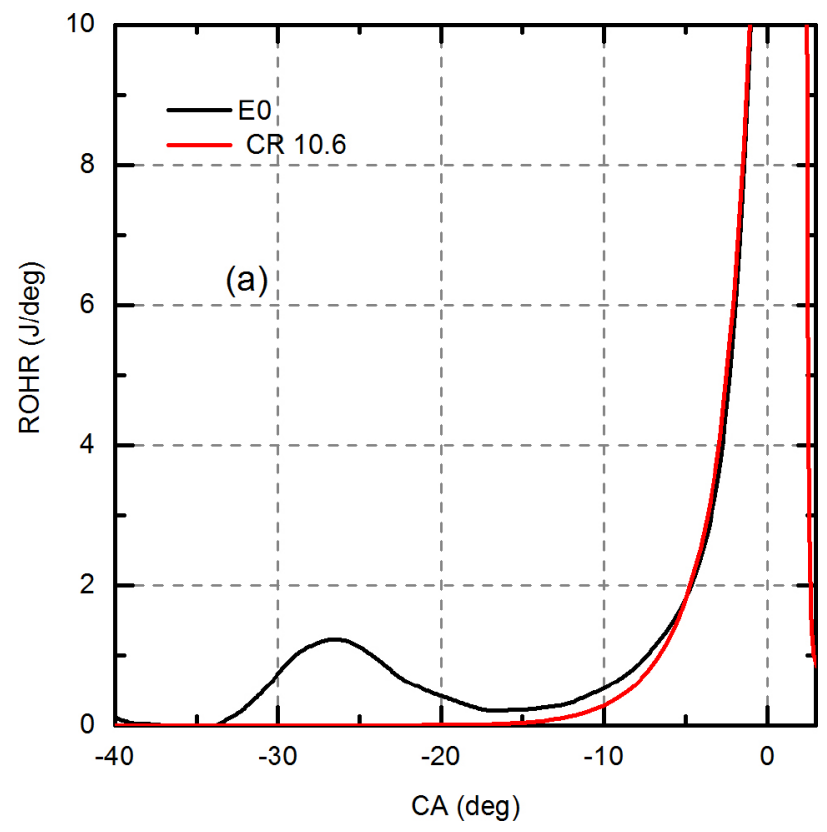

Figure A4a. Experimental (black) and simulated (red) rate of heat release for PRF70. Compression ratio used in simulation is given in legend. $900 \mathrm{rpm}$ $\mathrm{T}_{\text {intake }}=149 \mathrm{C} \mathrm{T} \mathrm{T}_{\mathrm{ivc}}$ (estimated) $188 \mathrm{C}$. 


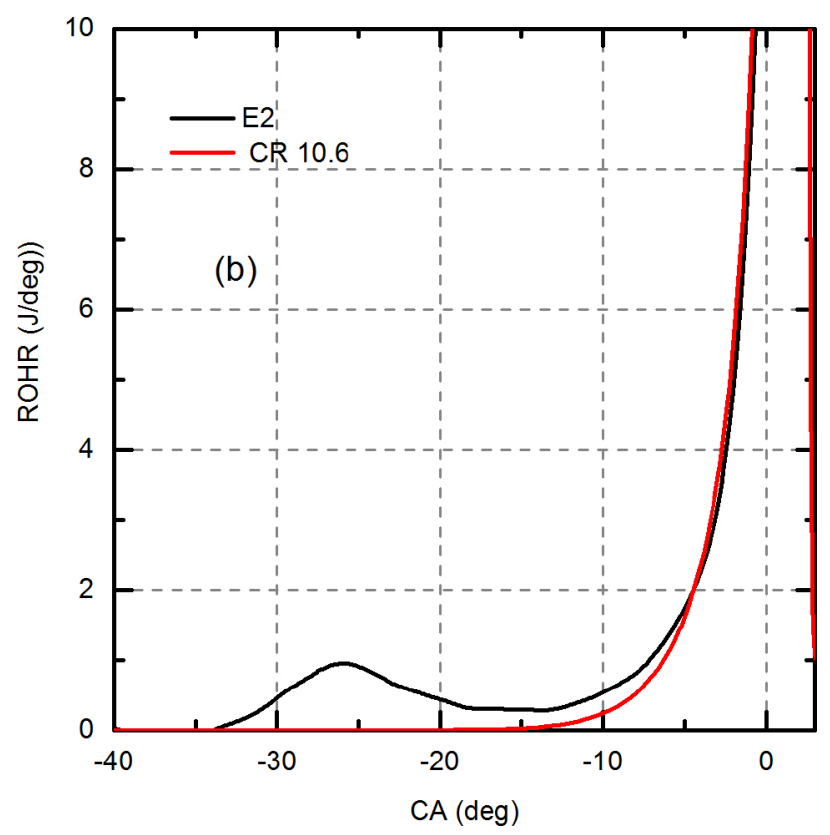

Figure A4b. Experimental (black) and simulated (red) rate of heat release for PRF70. Compression ratio used in simulation is given in legend. $900 \mathrm{rpm}$ $\mathrm{T}_{\text {intake }}=149 \mathrm{C} \mathrm{T}_{\mathrm{ivc}}$ (estimated) $188 \mathrm{C}$.

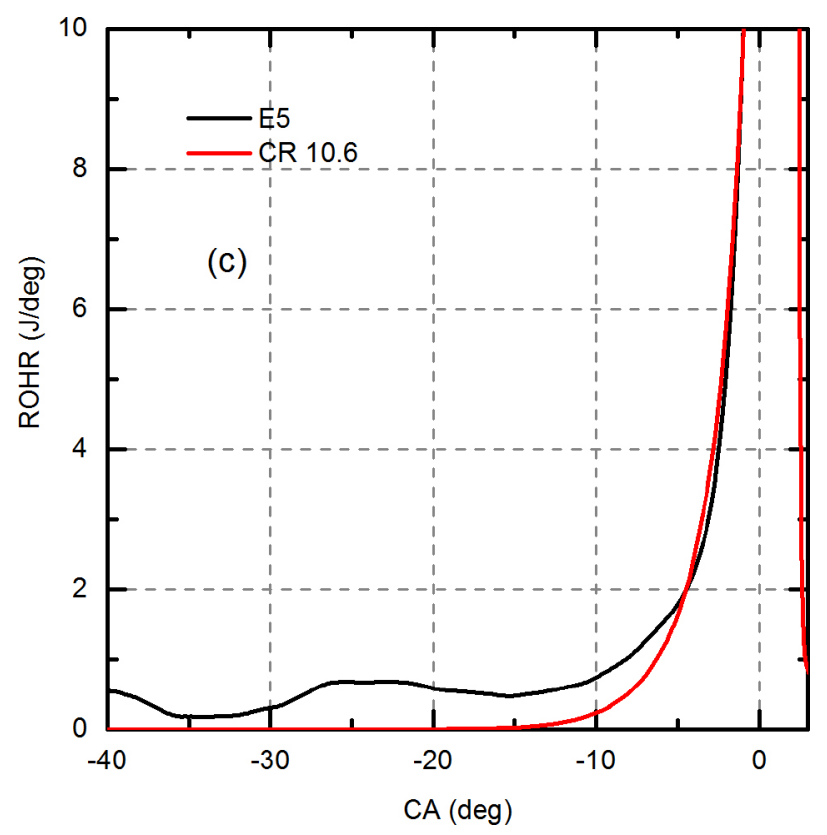

Figure A4c. Experimental (black) and simulated (red) rate of heat release for PRF70. Compression ratio used in simulation is given in legend. $900 \mathrm{rpm}$ $\mathrm{T}_{\text {intake }}=149 \mathrm{C} \mathrm{T} \mathrm{T}_{\mathrm{ivc}}$ (estimated) $188 \mathrm{C}$. 


\section{APPENDIX 3: MOTORED PRESSURE TRACE FOR ALL THE CONDITIONS}

Figure A1 represents the motoring curves used in the current work. The simulated compression ratio were achieved by having air in engine and matching the motor traces given below. It was assured that pressure at intake valve closure (IVC) and peak pressure were closely matched. These figures refer to the various cases discussed in the main text. The compression ratio corresponding to ethanol addition is mentioned in parenthesis next to the fuel tested.

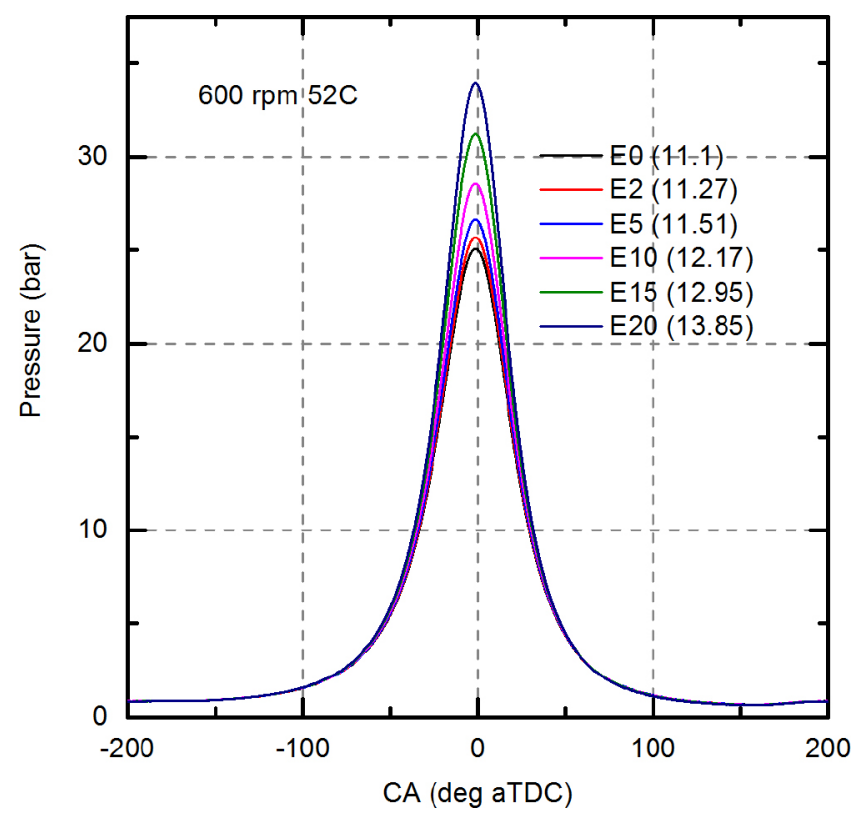

Figure A5. Motored pressure - CAD diagram for $600 \mathrm{rpm}$ 52C intake temperature

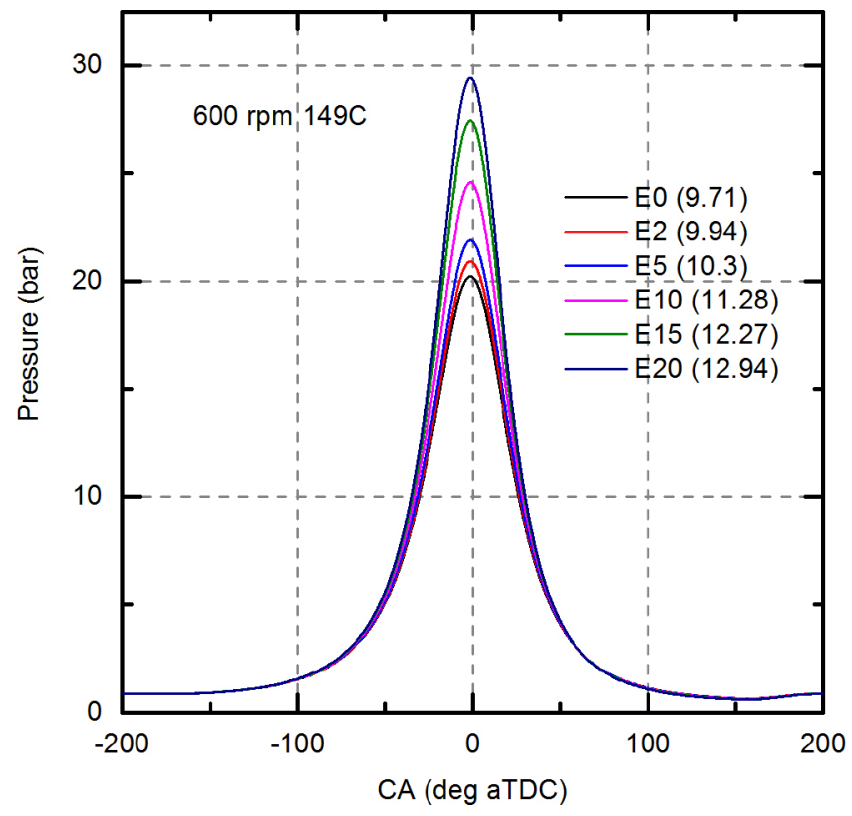

Figure A6. Motored pressure - CAD diagram for $600 \mathrm{rpm}$ 149C intake temperature 


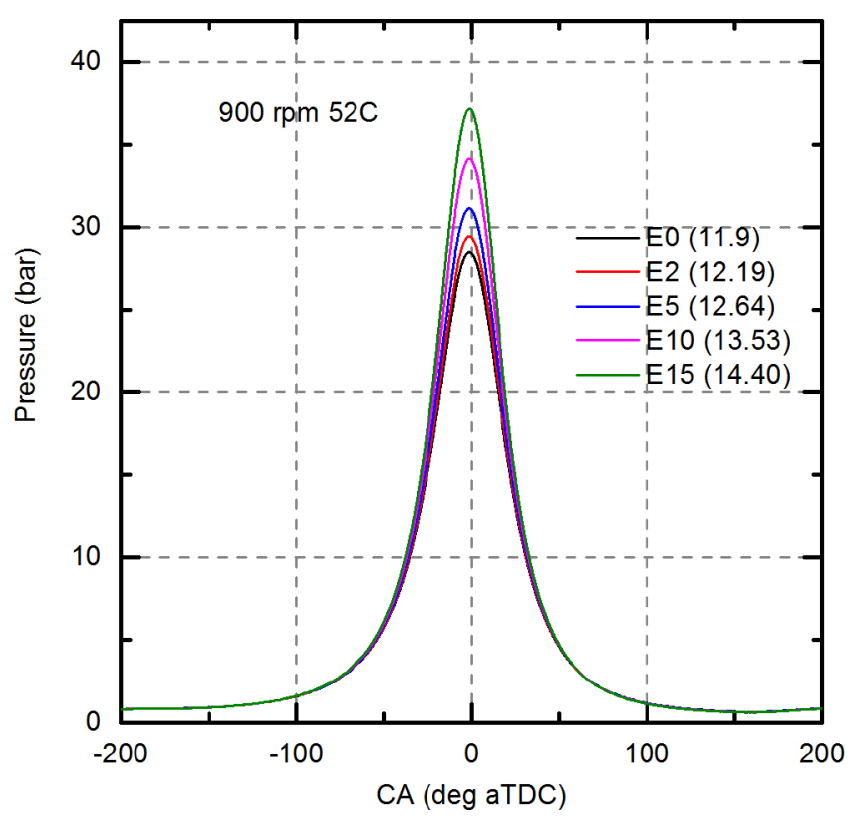

Figure A7. Motored pressure - CAD diagram for $900 \mathrm{rpm} 52 \mathrm{C}$ intake temperature

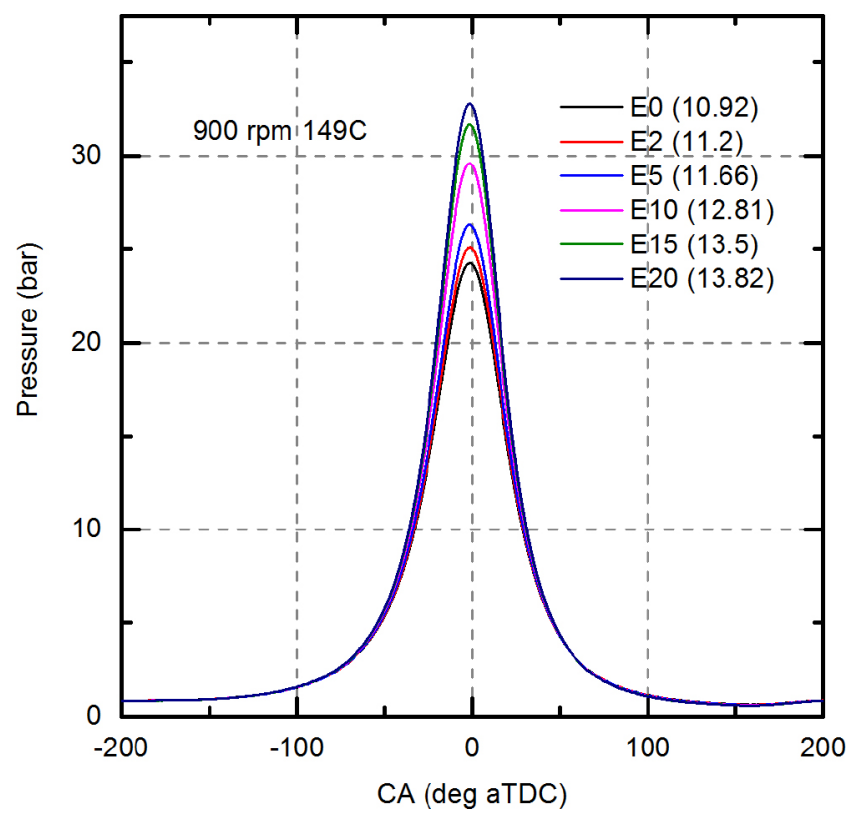

Figure A8. Motored pressure - CAD diagram for 900 rpm 149C intake temperature

The Engineering Meetings Board has approved this paper for publication. It has successfully completed SAE's peer review process under the supervision of the session organizer. The process requires a minimum of three (3) reviews by industry experts.

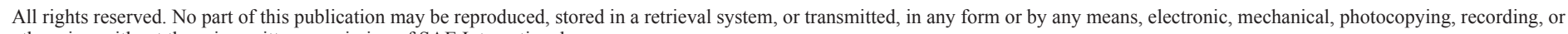
otherwise, without the prior written permission of SAE International.

Positions and opinions advanced in this paper are those of the author(s) and not necessarily those of SAE International. The author is solely responsible for the content of the paper.

ISSN 0148-7191

http://papers.sae.org/2017-01-0734 